Alma Mater Studiorum - Università di Bologna DEPARTMENT OF ECONOMICS

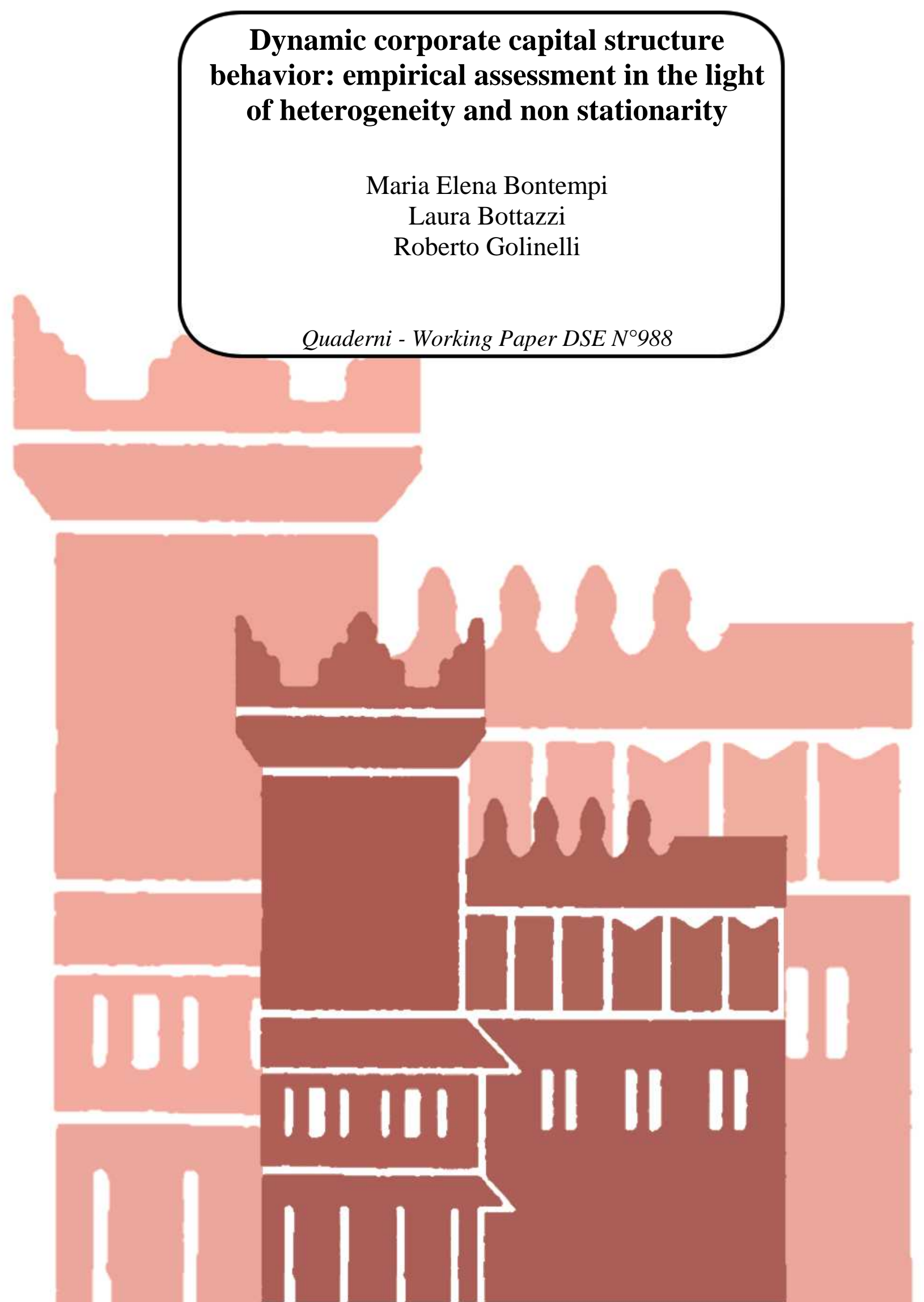




\title{
Dynamic corporate capital structure behavior: empirical assessment in the light of heterogeneity and non stationarity
}

\author{
Maria Elena Bontempi ${ }^{*}$, Laura Bottazzi ${ }^{* *}$, and Roberto Golinelli*
}

$1 / 14 / 2015$

\begin{abstract}
Understanding the dynamics of the leverage ratio is at the heart of the empirical research about firms' capital structure, as they can be very different under alternative theoretical models. The pillars of almost all empirical applications are the maintained assumptions of poolability and stationarity, which are motivated by the need of model's simplicity and treatability, rather than being based on an empirical ground. In this paper we provide robust evidence of non-stationarity for a significantly large share of US firms' debt ratios and of strong heterogeneity in the speeds at which firms adjust towards their targets. These results stimulate new directions of the empirical research on debt ratio dynamics by relying more on the concept of heterogeneous degree of leverage persistence.
\end{abstract}

Keywords: Corporate finance; Heterogeneity of agents; Target leverage; Speed of adjustment; Unit roots and cointegration;

JEL Classification: G32, C12, C22, C23, C51

* Department of Economics, University of Bologna, Italy

** Department of Economics, University of Bologna and IGIER-Bocconi, Italy 


\section{Introduction ${ }^{1}$}

The empirical assessment of leverage dynamics is at the heart of the research on corporate capital structure, and is well grounded in three main theoretical approaches: the Trade-Off theory (henceforth TO, Bradley et al., 1984; Harris and Raviv, 1991), the Pecking-Order theory (henceforth PO, Myers and Majluf, 1984) and the Market-Timing theory (henceforth MT, Baker and Wurgler, 2002). TO theory predicts that the leverage ratio changes to bridge the gap between the actual and the optimal leverage ratio, the latter being determined by balancing the costs (for example, default costs) and the benefits (for example, tax savings due to the deductibility of interest paid) of borrowing. PO theory envisages that the leverage ratio changes to fulfill the need for investment financing when internal funds prove insufficient. Finally, the MT theory predicts that the leverage ratio changes to time the equity markets: when the market is perceived to be advantageous, the leverage ratio is reduced by raising equity capital. Different borrowing dynamics emerge out of the three approaches: TO theory predicts that the corporate debt ratio reverts to an optimal target, while both PO and MT theories do not entail such an adjustment.

Since the seminal works of Taggart (1977) and Auerbach (1985) to the recent studies of Fama and French (2012) and Frank and Shen (2014), a relevant amount of empirical research has been (and is still) devoted to assess whether leverage dynamics fluctuate or not around an optimal target or, equivalently, if the speed of adjustment (henceforth SOA) of actual toward target debt is either significant or zero. Surveys of this huge literature are in Graham and Leary (2012), Parsons and Titman (2008), and Frank and Goyal (2008). The latter authors summarize the bulk of empirical findings with their stylized fact \#11: "Corporate leverage is mean-reverting at the firm level. The speed at which this happens is not a settled issue". The first part of the sentence is supported by the outcome of many published empirical papers. The second part is motivated by the different dynamic models used in these papers, ranging from the classical linear adjustment model to alternative non-linear and asymmetric adjustment models. Given the wide spectrum of empirical evidence about the dynamics of the corporate leverage, we try to summarize main findings and critical points.

Linear models usually find significant and quite slow SOAs of actual to target leverage ("snail's pace" and "practically no-readjustment" respectively in the words of Fama and French

\footnotetext{
${ }^{1}$ Preliminary drafts of this paper were presented at $1{ }^{\text {st }}$ Conference on Recent Developments in Financial Econometrics and Applications, Deakin University, Geelong Waterfront Campus, Melbourne, Australia, 4-5, December, 2014, and at the $6^{\text {th }}$ Italian Congress of Econometrics and Empirical Economics (ICEEE), Salerno, Italy, January 21-23, 2015. We are grateful, without implication, to Mauro Costantini as well as to conferences' participants for their comments and suggestions.
} 
(2002) and of Welch (2004)). ${ }^{2}$ The recent works by Elsas and Florysiak (2014) and Flannery and Watson Hankins (2013) compare the statistical performance of alternative estimators for dynamic linear models, and implicitly support this specification.

Models with non-linear or asymmetric adjustments always find significant departures from linearity, and cast doubts on the linear specifications' ability to explain debt dynamics under both the statistical and the economic perspective. Further, the evidence in Chang and Dasgupta (2009) and Hovakimian and Li (2011) warns against the empirical validity of inferences based on linear target adjusting models, and DeAngelo and Roll (2013) point to the instability of their leverage relationships' estimates. Overall, Graham and Leary (2011) summarize these negative findings by acknowledging that: "Estimates of leverage adjustment speeds are biased (theme \#6)", and that: "Capital structure dynamics have not been adequately considered (theme \#7)". In synthesis, they strongly oppose the previously cited stylized fact \#11 of Frank and Goyal (2008).

Independently on being supportive or not of linear target adjustment dynamics, all the studies above rely on two maintained assumptions: the poolability of the SOA parameters and the stationarity of the debt ratio and of the main explanatory variables (like profitability or investment opportunities). These two hypotheses are implicit in the derivation of the empirical specifications from theoretical dynamic capital structure models, but rarely have been tested on actual data. ${ }^{3}$ In spite of Graham and Leary (2011) warning that models with pooled SOAs have limited informative value, since poolability assumes that all firms have the same adjustment costs, answers have not yet emerged about the issue of how to select sub-samples of firms with "homogeneous" adjustment costs without incurring in ad hoc assumptions. Although some papers ${ }^{4}$ claim to tackle the issue of heterogeneity, they simply split the whole sample in few sub-samples selected a priori and/or use models with firm-specific effects that - as we show - cannot emend for the issue of SOA heterogeneity. ${ }^{5}$

Neglecting SOAs heterogeneity when, instead, a share of firms is not reverting to target leverages can explain most of the problems emerging from the empirical literature's review: 1. statistically significant SOAs which, however, are extremely slow; 2. instability of the SOAs; 3.the awkward interpretation of the target leverage determinants. For example, the slow SOAs

\footnotetext{
${ }^{2}$ Flannery and Rangan (2006) estimate only marginally faster SOAs.

${ }^{3}$ Note that a great deal of persistence and non-stationarity has been found by studies inspecting the statistical properties of alternative financial and profitability ratios: Ioannidis et al. (2003), McLeay and Stevenson (2009), and Canarella et al. (2013).

${ }^{4}$ See e.g. Shyam-Sunder and Myers (1999), Frank and Goyal (2003), Lemmon et al. (2008), and Antoniou et al. (2008).

${ }^{5}$ As far as we know, only two papers quote and partially account for the Graham and Leary (2011) argument. Elsas and Florysiak (2014) acknowledge the need of avoiding the SOA parameters' pooling for companies with too strongly different adjustment costs, but they only introduce a new panel estimator with a better small-sample performance. Frank and Shen (2014) estimate individual target leverages with four common factors extracted from 146 variables with heterogeneous factor loadings, but they assume the same (pooled) SOA towards these targets.
} 
emphasized by Fama and French (2002) and Welch (2004) could come from invalid pooling of firms actually belonging to two groups: those adjusting to targets, and those not-adjusting at all. In addition, if the two shares of firms vary over time, the pooled SOA estimates could be subject to model parameters' instability, as found in De Angelo and Roll (2013). In the context of lacking cointegration, strongly significant SOA parameters might be due to the invalid use of t-statistics in the non-stationary context where, instead, unit roots and cointegration tests should have been used to assess the role of the leverage determinants. Further, a lack of cointegration between leverage and its determinants could also explain the parameters' instability found in De Angelo and Roll (2013), and sheds light on the awkward outcomes of the random financing simulations in Chang and Dasgupta (2009).

The aim of our paper is to assess the extent of invalid assumptions of poolability and stationarity which can contaminate SOA estimates and inferences and to propose alternative specifications of leverage dynamics in which parameters are allowed to vary across firms using methodological approaches that do not assume a priori variables' stationarity but, instead, test for it.

Our main results are three. First, we find non-stationarity of a large share of US firms' leverage ratios: at single-firm level, target-adjustment dynamics do not seem to be particularly common. ${ }^{6}$ Second, the heterogeneity of SOA estimates is evident and significant, with a prevalence of SOAs not significantly different from zero. Third, when we model the dynamics of short and long term debt ratios separately, we find that non-stationarity affects more the latter. However, short- and long-term average SOA estimates of those firms which are target reverting are not much different from each other, and across alternative heterogeneous specifications.

Overall, our evidence points to very persistent and heterogeneous dynamics that, coupled with a significant share of firms with non-stationary leverages (i.e. with zero SOAs), calls for capital structure models which should better account for the dichotomy of reverting and nonreverting firms (i.e. of non-zero and zero SOAs). Therefore, the empirical approaches neglecting these issues are prone to find dubious (i.e. puzzling, unstable or arbitrary) evidence of the target adjustment mechanisms. ${ }^{7}$

The rest of the paper is organized as follows. Section 2 which is complemented by Appendix A1 sketches the main features of the pooled dynamic models used in the empirical literature on capital structure, ranging from the linear to the non-linear and the asymmetric adjustment models.

\footnotetext{
${ }^{6}$ Recently, also Eckbo and Kisser (2014) find little support to the target adjusting behavior from using models where the dependent variable is debt issues rather than the usual changes in leverage ratios.

${ }^{7}$ For example, when we compute, using our unrestricted individual estimates, the average SOA of the reverting companies, we obtain a measure of speed which is markedly higher than the one usually reported in the literature, and close to the results in Frank and Shen (2014) who, at least, account for the heterogeneity of target determinants
} 
This review aims to provide the reader with information on the extant models and the benchmark of our heterogeneous approach with possibly non-stationary variables.

Section 3 lists five alternative specifications of debt dynamics with heterogeneous speeds of adjustment. The heterogeneity assumption requires a very parsimonious model because the inference, which is conducted at the firm level, exploits the time-series variability of each company at a time. We propose various specifications of the simple, but effective, univariate representation of the debt ratio dynamics which extends the linear approach of Bontempi and Golinelli $(2012)^{8}$ In particular, Section 3.1 makes use of Bontempi and Golinelli (2012) linear implementation, while Section 3.2 extends it to different forms of asymmetry and/or exponential smoothing transition in the presence of leverage determinants that are stationary. Section 3.3 considers leverage nonstationarity due to one or two relevant events (breaks) occurring during the life of the firm. Section 3.4 explains individual debt ratios as dynamically adjusting to targets measured by industry-wide averages (details are in Appendix A2). Section 3.5 introduces alternative cointegration tests to assess the relevance of the inclusion of explicit target leverage determinants. Section 4 lists the empirical outcomes: single-company unit-root (Section 4.1) and cointegration (Section 4.2) results are summarized by estimating the shares of the target reverting firms and their average SOAs in alternative balanced panels drawn from Compustat dataset (described in Appendix A3). Finally we test for the stability over time of our results by running the previous procedures over rolling windows (Section 4.3). Section 5 summarizes the main findings and discusses possible extensions of this research.

\section{A review of the literature about capital structure dynamics}

Much of the empirical capital structure literature can be summarized by the following reduced-form ${ }^{9}$ representation of leverage changes, $\Delta L$, in a panel of firms $(i=1,2, \ldots, N)$ observed over an enough long time span $(t=1,2, \ldots, T):^{10}$

$$
\Delta L_{i t}=\eta_{i t}+\gamma_{i t}^{\prime} X_{i t}^{P O / M T}+\alpha_{i t}\left(L_{i t-1}-L_{i t-1}^{*}\right), \quad \text { with: } L_{i t}^{*}=\beta_{i t}^{\prime} Z_{i t}^{T O}
$$

where $L$ and $L^{*}$ are, respectively, the observed and the optimal leverage ratios; $X^{P O / M T}$ is a vector of variables able to affect the short run dynamics of leverage, as suggested by the Pecking-

\footnotetext{
${ }^{8}$ In particular, they show that the unit root tests of Dickey and Fuller (1979) and of Elliott et al. (1996), if computed at single-firm time series level, can measure and test companies' SOAs in the heterogeneous context.

${ }^{9}$ In what follows, we will focus on reduced form approaches, and not on dynamic structural models of capital structure. For a sort of workhorse in the structural modeling field see Korteweg and Lemmon (2013).

${ }^{10}$ As quite usual in literature, equation (1) explains the borrowing by individual firms as a continuous process of changes in debt ratios, rather than discrete issuances and repurchases. For the opposite point of view, see Eckbo and Kisser (2014).
} 
Order (PO) and Market-Timing (MT) theories. In particular, PO variables measure the need for investment financing not funded by retained earnings (i.e. according to the flow of funds deficit), and MT variables measure the timing of the equity markets (i.e. when the market is perceived to be advantageous, debt ratio is reduced by raising equity capital). $Z^{T O}$ is a vector of variables determining the optimal debt ratio derived by balancing the costs (for example, default costs) and the benefits of borrowing (for example, tax savings due to the deductibility of interest paid), as predicted by the Trade Off (TO) theory.

In model (1), $\gamma, \alpha$, and $\beta$ are unobservable components measuring the impact of the PO/MT and of the TO explanatory variables on leverage and, depending on the approach, they may be modeled as parameters or as linear/nonlinear functions of variables. The term $\eta$ includes any other unobservable determinant of leverage changes and it is added to avoid biases from the omission of relevant variables.

The restriction most commonly imposed to equation (1) regards the pooling of model's slopes, together with the assumption of the presence of individual $\mu_{i}$, time $\tau_{t}$, and idiosyncratic $\varepsilon_{i t}$ effects:

$$
\gamma_{i t}=\gamma ; \alpha_{i t}=\alpha ; \beta_{i t}=\beta ; \eta_{i t}=\mu_{i}+\tau_{t}+\varepsilon_{i t}
$$

Substituting the restrictions (2) in the general specification (1), we obtain the linear dynamic model:

$$
\Delta L_{i t}=\mu_{i}+\tau_{t}+\gamma X_{i t}^{P O / M T}+\alpha\left(L_{i t-1}-\beta Z_{i t-1}^{T O}\right)+\varepsilon_{i t}
$$

In the linear model (3), the heterogeneity in $L_{i t}$ is explained by the PO/MT and TO determinants $X_{i t}^{P O / M T}$ and $Z_{i t}^{T O}$, by the individual effects $\mu_{i}$, by the macroeconomic shocks $\tau_{t}$ and by the idiosyncratic errors $\varepsilon_{i t}$, while the slope parameters $\gamma, \alpha$, and $\beta$ are assumed to be fixed across individuals and over time. All firms are assumed to adjust at the same pace $\alpha$, the so called speed of adjustment (SOA). The statistical significance of SOA is generally interpreted as "target adjustment behavior" or, in other terms, as "valid TO model": a non-zero SOA supports the existence of an optimal target debt as motivated by the TO theories. Despite the issues and shortcomings listed in Appendix A1, model (3) is the workhorse of the empirical specifications used to quantitatively study the dynamic of capital structure. ${ }^{11}$

\footnotetext{
${ }^{11}$ Even limiting to the published articles based on Compustat data, we can, not exhaustively, list twelve papers: Auerbach (1985), Shyam-Sunder and Myers (1999), Fama and French (2002), Frank and Goyal (2003), Welch (2004), Flannery and Rangan (2006), Hovakimian (2006), Kayan and Titman (2007), Lemmon et al. (2008), Huang and Ritter (2009), de Jong et al. (2011), Fama and French (2012). Assumptions (2) are usually used also for the non-US case:
} 
More recently, several papers propose nonlinear leverage models whose estimation results have been emphasized as being more reliable and reasonable than those of the linear model. The main specification changes to model (3) have to do with parameter shifts modeled in alternative ways, ranging from traditional variables interactions to maximum likelihood estimates of regimeswitching models (with threshold parameters or driven by thresholds of intervention). ${ }^{12}$ In symbols, these extensions imply the replacement of assumptions (2) - at the basis of the linear adjustment model - with the following less restrictive assumptions:

$$
\gamma_{i t}=\gamma\left(W_{i t}\right) ; \alpha_{i t}=\alpha\left(W_{i t}\right) ; \beta_{i t}=\beta\left(W_{i t}\right)
$$

Compared to the linear context, here $\gamma, \alpha$, and $\beta$ are no longer considered fixed over time and poolable across individuals, but are allowed to evolve as a function of a number of firm-, industry-, or macroeconomic-specific determinants $W_{i t}{ }^{13}$ which are related with transaction and adjustment costs. The two assumptions on which this "nonlinear adjustment" literature is based are: (1) the TO theory is a valid representation of data assumed to be stationary; (2) unexplained parameters heterogeneity is driven solely by few and known a priori chosen variables $W .{ }^{14}$ Hence, this new strand of literature still assumes stationarity and poolability.

As a matter of fact, the empirical findings based on the linear and non-linear models cited above raise many issues (see the list in Appendix A1) but their results do not provide a clear and robust statement about SOA estimates which are still presently a puzzle.

\section{Extending the state-of-art models to heterogeneity under alternative degrees of persistence}

From the statistical point of view, the empirical literature on capital structure based on the pooled model (3) relies on the asymptotic of large $N$ and small $T$ panel estimation which admits fixed- or random-effects estimators, or a combination of fixed-effects and instrumental-variable estimators. Besides stationarity, these methods require pooling individual group slopes (i.e. only

Bontempi (1999) for Italy, de Miguel and Pindado (2001) for Spain, Ozkan (2001) and Bevan and Danbolt (2002) for the UK, Gaud et al. (2007) for Europe, Nunkoo and Boateng (2010) for Canada, Guney et al. (2011) for China, and Noulas and Genimakis (2011) for Greece. Antoniou et al. (2008) compare the results between bank-oriented (France, Germany, Japan) and market-oriented (US, and UK) countries.

${ }^{12}$ De Angelo and Roll (2013) label the latter as "target zone models".

${ }^{13}$ For example, in the case of the simple model with interactions, the SOA is modeled as a linear function of the $K$ drivers in $W^{(k)}: \alpha_{i t}=\alpha_{0}+\sum_{k=1}^{K} \alpha_{k} W_{i t}^{(k)}$, where $\alpha_{0}$ is the linear SOA of model (3) when $\alpha_{k}=0 \forall k$.

${ }^{14}$ This strand of literature counts a long and non exhaustive list: Fisher et al. (1989), Gilson (1997), Roberts (2002), de Haas and Peeters (2006), Drobetz and Wanzenried (2006), Byoun (2008), Cook and Tang (2010), DeAngelo et al. (2011), Elsas and Florysiak (2011), Aybar-Arias et al. (2012), Dang et al. (2012), Faulkender et al. (2012), Halling et al. (2012), Korteweg and Strebulaev (2012), Warr et al. (2012), Baum et al. (2014). Recently, Pereira-Alves and Ferreira (2011), and Oztekin and Flannery (2012) use dummy interactions to extend the international comparison (in the linear model context) of Antoniou et al. (2008) to explore the effect of country-specific institutional determinants. 
the intercepts can differ across the groups). However, with the increase in time observations $T$ of large $N$ panels, not only nonstationarity concern grows, but also the assumption of homogeneity of slope parameters becomes inappropriate (see Pesaran and Smith (1995), Pesaran et al. (1999), and Phillips and Moon (2000)). In this context of "unavoidable" heterogeneity, the asymptotic of large $N$ large $T$ motivates our approach of using individual time series estimators in two respects. First, heterogeneous parameter estimates are the basic ingredient of the unbiased mean estimator of Pesaran and Smith (1995) and Pesaran, et al. (1999). Second, Costantini and Lupi (2014) find that individual time series-based inferences are one of the most efficient classification tools for the individuals belonging to a panel of data. ${ }^{15}$

Therefore, in this paper we propose a way to reinterpret much of the previous results extant in the literature on the basis of very simple time series models of leverage dynamics under the assumptions of heterogeneity and possible non stationarity. We check for reversion of actual debt towards the target in the context of parameters' full heterogeneity across firms by using testing strategies that are still valid in the presence of unit-roots (i.e. no adjustment toward targets). In particular, we provide an approach of estimating and testing for the significance of individual SOAs in the context of either linear or non-linear models with stationary explanatory TO determinants (cases A1 and A2 in Section 3.1 and 3.2), and of linear adjustments with non-stationary explanatory TO determinants. The non-stationarity property of the variables can be alternatively due to breaking targets (case B1 in Section 3.3), to firms adjusting towards average ratios by sector (case B2 in Section 3.4), and to non-stationary, but cointegrated with leverage ratios, TO determinants (case C1 in Section 3.5).

Starting from the general model (1), heterogeneity of debt dynamics can be allowed across individuals (but not over time) ${ }^{16}$ by assuming the following restrictions:

$$
\gamma_{i t}=\gamma_{i} ; \alpha_{i t}=\alpha_{i} ; \beta_{i t}=\beta_{i} ; \eta_{i t}=\mu_{i}+\varepsilon_{i t}
$$

Restrictions (5) correspond to the assumption that PO/MT and TO driving forces are measured by firm-specific parameters which are constant over time. By substituting restrictions (5) in equation (1) we obtain the linear model:

$$
\Delta L_{i t}=\mu_{i}+\gamma_{i} X_{i t}^{P O / M T}+\alpha_{i}\left(L_{i t-1}-\beta_{i} Z_{i t-1}^{T O}\right)+\varepsilon_{i t}
$$

Model (6) is the heterogeneous counterpart of the classical pooled model (3), in which the latter is nested. Imposing the assumption of poolability, $\gamma_{i}=\gamma, \alpha_{i}=\alpha$, and $\beta_{i}=\beta$ on model

\footnotetext{
${ }^{15}$ On the latter issue, see also Chortareas and Kapetanios (2009).

${ }^{16}$ The hypothesis of time invariance of our heterogeneous parameters will be validated in the empirical part of this study by estimating the models over recursive and rolling samples.
} 
(6) unavoidably leads to inconsistent parameter estimates because the explanatory variables are correlated with the error (see e.g. Pesaran and Smith (1995), and Imbs et al. (2005)):

$$
\begin{aligned}
\Delta L_{i t}= & \mu_{i}+\gamma X_{i t}^{P O / M T}+\alpha\left(L_{i t-1}-\beta Z_{i t-1}^{T O}\right)+ \\
\mathcal{E}_{i t}+ & {\left[\delta_{i}^{P O / M T} X_{i t}^{P O / M T}+\delta_{i} L_{i t-1}-\delta_{i} \beta Z_{i t-1}^{T O}-\left(\alpha+\delta_{i}\right) \delta_{i}^{T O} Z_{i t-1}^{T O}\right] }
\end{aligned}
$$

where the second row of equation (7) lists all the components of the error term under invalid poolability. The expression in squared brackets is the error component due to not-modelled heterogeneity defined as: $\gamma_{i}=\gamma+\delta_{i}^{P O / M T}, \alpha_{i}=\alpha+\delta_{i}$, and $\beta_{i}=\beta+\delta_{i}^{T O}$. Therefore, the poolability restrictions can be restated as: $\delta_{i}^{P O / M T}=\delta_{i}=\delta_{i}^{T O}=0 \quad \forall i$; under such restrictions the expression in squared brackets vanishes and equation (7) collapses to model (3). Under parameters' heterogeneity, inconsistent estimates arise even if we estimate nonlinear specifications of pooled debt equations, as non-linearity per se cannot prevent the problems of invalid poolability restrictions.

In this paper, we suggest the alternative approach of estimating model (6) and obtaining heterogeneous and consistent estimates. From the economic point of view, simulation results reported in Titman and Tsyplakov (2007) support our approach, as they suggest that the empirical research on the determinants of capital structure should estimate regressions on different subsamples representing different categories of firms. They show that the speed at which a firm's debt ratio reverts to its target, as well as the extent to which it moves away from its target, depends on the firm's susceptibility to financial distress, as well as on individual firms' (and possibly heterogeneous) characteristics. Further, the advocates of the "spurious" mean-reversion/targetadjustment (e.g. Chang and Dasgupta (2009) and Hovakimian and Li (2011)) always show their results in the pooled context, while our heterogeneous time series models exploit only the information on the pattern of leverage over time and, in doing so, are free from risks of invalid cross-section pooling.

Given that model (6) estimates are inefficient because all parameters are allowed to vary across companies, it is impossible to make reliable inferences unless very long time series by company are available. A possible way to bypass the problem of making estimates and inferences with single-company time series data is to reduce the number of parameters to be estimated. Given that the main interest here is in making inferences on the SOA, we can assume, without loss of generality, that PO/MT and TO determinants are summarized by two variables which admit a valid autoregressive (AR) representation: 


$$
\begin{aligned}
& a_{i}(L) X_{i t}^{P O / M T}=\varepsilon_{i t}^{P O / M T} \\
& b_{i}(L) Z_{i t}^{T O}=\varepsilon_{i t}^{T O}
\end{aligned}
$$

where $X_{i t}^{P O / M T}$ and $Z_{i t}^{T O}$ are characterized by heterogeneous inertia, represented as $a_{i}(L)$ and $b_{i}(L)$ polynomials in the lag operator $L$, and by the white noise random shocks $\varepsilon_{i t}^{P O / M T}$ and $\varepsilon_{i t}^{T O}$ assumed to be unrelated to $L_{i t-1}$. Depending on the stationary/integrated status of the data generation process of the drivers $X_{i t}^{P O / M T}$ and $Z_{i t}^{T O}$, different modeling options emerge.

Regarding the PO/MT determinants $X_{i t}^{P O / M T}$, the hypothesis of their stationarity does not seem particularly awkward, as a number of studies support the stationarity of PO/MT variables. For example, Raymar (1991) and Sarkar and Zapatero (2003) introduce theoretical models where earning processes are heterogeneous but mean-reverting; Alti (2006) shows that the impact of MT on leverage vanishes at the end of the second year: such limited persistence of MT shocks justifies the stationary assumption on $a_{i}(L)$ polynomials.

Therefore, in the following we will focus on cases in which only the TO drivers $Z_{i t}^{T O}$ are either stationary or not.

\section{1 - Case A1: stationary TO determinants in the linear context}

We can exploit Wold representations (8) of AR models to replace in the linear equation (6) both PO/MT and TO explanatory variables, assumed to be stationary. After rearranging, we can obtain a very parsimonious and linear univariate AR(1) representation of the individual company's debt ratio:

$$
\Delta L_{i t}=\alpha_{i} L_{i t-1}+\mu_{i}+e_{i t}
$$

where errors $e_{i t}$ combine the distributed lags of PO/MT and TO random shocks $\varepsilon_{i t}^{P O / M T}$ and $\varepsilon_{i t}^{T O}$ with the actual leverage shocks $\varepsilon_{i t}: e_{i t}=\gamma_{i} \frac{\varepsilon_{i t}^{P O / M T}}{a_{i}(L)}-\alpha_{i} \beta_{i} \frac{\varepsilon_{i t-1}^{T O}}{b_{i}(L)}+\varepsilon_{i t}$.

Given that $e_{i t}$ are autocorrelated, the correlation between $L_{i t-1}$ and $e_{i t}$ would entail inconsistent estimates of SOA in model (9). The autocorrelation of errors in (9) can be fixed by augmenting the model dynamics with an appropriate number of lags of the dependent variable $\Delta L_{i t}$. In this way, we obtain the $\operatorname{AR}\left(p_{i}+1\right)$ process:

$$
\Delta L_{i t}=\alpha_{i} L_{i t-1}+\mu_{i}+\sum_{j=1}^{p_{i}} \lambda_{i j} \Delta L_{i t-j}+v_{i t}
$$


It is worth noting that, in model (10), the meaning of the $\alpha_{i}$ parameter is the same as in model (6), and that the $\lambda_{i j}$ parameters measures the reduced-form dynamics in (8) of PO/MT and TO determinants as we assumed them to be both stationary.

The simple and heterogeneous univariate model (10) can parsimoniously summarize, through the heterogeneous $\alpha_{i}$ parameter, both TO and PO/MT stylized facts in the linear and stationary context.

When $\alpha_{i}<0$, model (10) suggests that the TO prediction is valid: companies borrow in order to gradually adjust towards their optimal debt ratios, assumed to be constant and equal to $L_{i}^{*}=\frac{\mu_{i}}{-\alpha_{i}}$, while random idiosyncratic shocks $v_{i t}$ have only transitory effects on the firms' financial structure. More precisely, $\alpha_{i}<0$ supports debt ratios stationarity and also corroborates the assumption that $Z_{i t}^{T O}$ is actually stationary.

When $\alpha_{i}=0$ the behavior of model (10) is consistent with the PO/MT models only if TO determinants, $Z_{i t}^{T O}$, are stationary. In fact, only in such context, PO/MT models do not support the existence of a target debt ratio and of the adjustment towards it. Borrowing is not driven by any attempt to attain an optimal capital structure: it simply reflects the need for external and low-riskcost funds to finance investment projects (in the PO), or the outcome of timing the equity market (in the MT). Hence, random idiosyncratic shocks $v_{i t}$ have permanent effects on firms financial structure, since the actual debt ratio behaves as a stochastic trend driven by shocks faced year after year by the companies. ${ }^{17}$

In the fully stationary context, the inference regarding the heterogeneous $\alpha_{i}$ gives the answer as to which theory, TO or PO/MT, is better suited to explaining the $i^{\text {th }}$ company debt ratio. In other words, heterogeneous parameter estimates enable us to identify the share of firms whose behavior conforms to a specific theory, be it pure TO, or PO/MT.

\footnotetext{
${ }^{17}$ It could be argued that there is a non-zero probability that the PO/MT-like debt ratio will explode (the firm's solvency condition cannot be met). Nevertheless, from the theoretical point of view, Fama and French (2002) point out that there are certain forces preventing this to happen. Firms that pay dividends can maintain lower debt ratios by lowering payouts, while nonpayers may need to borrow more to finance investments but, given both current and future borrowing costs, they tend to preserve low-risk debt capacity until positive net cash flows arrive, or through financial slacks. From the empirical point of view, the conclusion that debt ratios are integrated processes cannot be true in a very strict sense because integrated series are unbounded, while debt ratios are bounded between zero and one. Nevertheless, when sample data suggest that the statistical characteristics of debt ratios are closer to integrated rather than stationary series, it is better to treat these series as if they had stochastic trends; see e.g. Hall et al. (1992). In addition, as noted in Brunello et al. (2000) regarding the estimates of the NAIRU, the relevant issue is not the fact that the variables are bounded from above by 1 and from below by 0 , but it is the time needed for the limits 0 and 1 to be binding. In our context, for reasonable values of the variance of debt shock $v_{i t}$, the expected time required for the barriers to be binding is extremely large (of an order of magnitude of about 1,700 years) and, during such a huge temporal interval, the debt ratio is exactly equivalent to an unrestricted random walk.
} 
Of course, parsimony and heterogeneity do not come without a cost: model (10) does not allow for the estimation of specific $\gamma_{i}$ and $\beta_{i}$ PO/MT and TO effects of equation (6), i.e. it does not extricate the relevance of the alternative theories in explaining debt fluctuations. Still, model (10) makes it possible to concentrate on the key empirical parameter of the SOA, which is of paramount interest because "it is important to analyze how quickly [corporations] revert to their target capital structure when moved away by random events.", Antoniou et al. (2008, p. 2).

On the other side, the parsimonious nature of model (10) prevents many of the problems common to those empirical studies based on model (3) panel estimates, namely: the cumbersome interpretation of a large number of estimation results related to (sometimes ad hoc) explanatory variables; the excess of statistical significance of parameters' estimates; the risk (which increase as model size increases) of measurement errors and of simultaneity, as shown by model (7) above, which is only apparently tackled by instruments (often weak); the occurrence of pooled inconsistent estimates discordant with the theoretical predictions. ${ }^{18}$

Equation (10) can be estimated firm by firm with OLS and, under the null that debt ratios are integrated, inferences on $\alpha_{i}$ parameters can be accomplished by using the distribution of the Dickey-Fuller (1979) test, henceforth ADF.

The practical issue of selecting $p_{i}$ in model (10) is tackled - here as well as in the other applications of this paper - by a data dependent procedure which starts from a maximum number of lags $p_{\max }$ and then sequentially tests down until the higher-lag parameter is $10 \%$ significant. This procedure, introduced by the seminal work of Campbell and Perron (1991), has been deepened by $\mathrm{Ng}$ and Perron (1995) who also showed the improvements in the size of the ADF test.

Table 1 summarizes the ADF test interpretation, and introduces the variants to model (10) which will be implemented below. Along the columns of Table 1 the two hypothetical scenarios of interest are depicted: in the PO/MT scenario (in the first column) firms do not follow the target leverage; in the TO scenario (in the second column) firms follow a constant target driven by TO determinants assumed to be stationary. Along the rows of Table 1 we list the two possible outcomes of the ADF test: rejection of the null hypothesis $\alpha_{i}=0$ (in the first row); not rejection of the null hypothesis $\alpha_{i}=0$ (in the second row). Along the main diagonal, the decisions based on ADF test results are right as they correctly interpret the underlying assumed states of the world.

\section{Table 1 here}

Outside the main diagonal, in the down-left quadrant, we acknowledge that some circumstances can trick ADF to reject PO/MT when it would actually be the best representation of

\footnotetext{
${ }^{18}$ The comments of Gordon (1985) to Auerbach (1985) model are along these lines.
} 
how firms behave. For example, the presence of sizeable MA terms in model (9) errors dynamics could weaken the ability of the testing down procedures to select the appropriate lag order $p_{i}$ of model (10). Although with annual data this case should not be frequent, we use, besides the ADF test, the Elliott et al. (1996) test (henceforth DFGLS) based on GLS detrended data which has excellent size and power properties in assessing the null $\alpha_{i}=0$ (see also $\mathrm{Ng}$ and Perron (2001)), and works well also in small samples. Other cases of ADF over-rejection are due to $\alpha_{i}$ estimates variability over time and to the presence of breaks near the beginning of the series. To keep under control the latter two circumstances, in Section 4.3 below we also estimate our models over rolling samples. In general, the problems of the performance of the ADF test listed in the down-left quadrant are mainly due to the structure of model (10) errors.

In the up-right quadrant we under-reject the false null hypothesis because of SOA nonlinearity (see case A2 below), shifts in the target leverage (see case B1), or non-stationary drivers of the target leverage (cases B2 and C1). In other terms, ADF test problems of power emerge because of specification errors of the model under the alternative hypothesis.

\section{2 - Case A2: stationary TO determinants in the non-linear context}

The SOA parameters could be time-varying or affected by some kinds of non-linearity. For example, the autoregressive decay specification could depend on the state of the debt ratio: if the SOA is fast when the firm is over-levered (i.e. when actual debt is above its target) and slow when it is under-levered, peaks would be less persistent than troughs, e.g. because of low adjustment costs. Thus, the heterogeneous linear model (10) with symmetric adjustment processes can be extended to allow for SOA non-linearity either in the form of asymmetric AR processes (where SOAs can be different if the firm is over- or under-levered with respect to the target), or in the form of exponential smooth transition AR processes (where SOAs get higher the farer actual leverage is from the target).

The asymmetric adjustment extension in the context of testing for unit roots (i.e. for no adjustment under the null hypothesis) has been introduced by Enders and Granger (1998), and reconsidered in Berben and van Dijk (1999), henceforth BvD. The threshold AR model (TAR) with asymmetric SOA is specified as:

$$
\Delta L_{i t}=\left\{\begin{array}{l|ll}
\alpha_{i}^{-}\left(L_{i t-1}-L_{i}^{*}\right)+\sum_{j=1}^{p_{i}} \lambda_{i j} \Delta L_{i t-j}+v_{i t} & \text { if } & L_{i t-1} \leq L_{i}^{*} \\
\alpha_{i}^{+}\left(L_{i t-1}-L_{i}^{*}\right)+\sum_{j=1}^{p_{i}} \lambda_{i j} \Delta L_{i t-j}+v_{i t} & \text { if } & L_{i t-1}>L_{i}^{*}
\end{array}\right.
$$


where we have two different heterogeneous SOA, $\alpha_{i}^{-}$and $\alpha_{i}^{+}$, for under- and over-levered firms in $t-1$, respectively. As with $\mathrm{ADF}$ test, the inclusion of $p_{i}$ lags aims to white noise idiosyncratic shocks $v_{i t}$. Model (11) may be seen as an extension towards heterogeneity of the non-linear approach of Warr et al. (2012) who report distinct SOA pooled estimates for the groups of firms over- and under-levered and over- and under-valued, and of Byoun (2008) who considers pooled SOA parameters for firms above (below) the target debt and with a financial surplus (deficit).

In case of known thresholds $L_{i}^{*}$, the speeds of adjustment and augmentation parameters of model (11) can be estimated with OLS. In our case, since the debt target $L_{i}^{*}$ is unknown and has to be estimated, we use the sequential conditional least squares suggested by BvD. This procedure chooses the estimate of $L_{i}^{*}$ (belonging to the $15 \%$ trimmed interval within the minimum and maximum historical value of the actual debt ratios) which minimizes the residuals variance, and then uses a statistic $\mathrm{F}$ (tabulated by BvD) to test for the null hypothesis of non stationarity: $\alpha_{i}^{-}=\alpha_{i}^{+}$ $=0 .{ }^{19}$ If the unit-root null is rejected, we can test for $\alpha_{i}^{-}=\alpha_{i}^{+}$(i.e. that the two speeds do not significantly differ) with a standard F statistic. ${ }^{20}$

By comparing the outcomes of ADF and BvD tests, ${ }^{21}$ the share of firms stationary according to the BvD test, but classified as non stationary by the ADF test, provides the gain in power of the test thanks to the asymmetry allowed under the alternative: for these companies, the assumption of asymmetric SOA is crucial for the understanding of their dynamics of adjustment.

Besides the BvD approach, we also use the Kapetanios et al. (2003) test (henceforth KSS). This test assumes, under the alternative, that the speed of adjustment is that of a stationary exponential smooth transition AR process (ESTAR):

$$
\Delta L_{i t}=\left(L_{i t-1}-L_{i}^{*}\right)\left(e^{-\theta_{i}\left(L_{i t-1}-L_{i}^{*}\right)^{2}}-1\right)+\sum_{j=1}^{p_{i}} \lambda_{i j} \Delta L_{i t-j}+v_{i t}
$$

where the nonlinear SOA in brackets is both heterogeneous and may vary over time, depending on the distance between actual and target debt ratios: $\alpha_{i t}=e^{-\theta_{i}\left(L_{i t-1}-L_{i}^{*}\right)^{2}}-1 .{ }^{22}$ In model (12), the unit

\footnotetext{
${ }^{19}$ The innovation of the BvD approach with respect to Enders and Granger (1998) is that of searching the target which minimizes the residuals variance of model (11), rather than of estimating the debt target with the sample mean of the actual data. When the strength of the adjustment towards the attractor $L^{*}$ is very different in the two regimes, the sample mean is a biased estimator of the target, and the Enders and Granger (1998) procedure may lack of power with respect to the standard unit roots approach (based on the linear AR).

${ }^{20}$ The linear specification under the null of the F test is a data congruent representation which is more parsimonious than the (unneeded) asymmetric adjustment model.

${ }^{21}$ We suggest comparing the BvD test outcome with that of ADF, rather than of DFGLS, because the ADF test equation (10) is nested in the nonlinear extension (11).

${ }^{22}$ As in the ADF test, the inclusion of pi lags in model (12) aims to reach white noise idiosyncratic shocks.
} 
root null corresponds to the hypothesis that $\theta_{i}=0$ (corresponding to $\alpha_{i t}=0$ ), against the alternative $\theta_{i}>0$, i.e. the larger the distance between actual and target debt, the larger the SOA. Note also that, under the alternative of nonlinear target adjustment, SOA is symmetric (as the speed of adjustment depends on the squared distance), and its non-linearity cannot be tested against the linear $\mathrm{ADF}$ test equation (as instead BvD approach does).

The KSS test equation (12) may be seen as an extension towards heterogeneity of the nonlinear approach of Korteweg and Strebulaev (2012), who developed a stationary and poolable (S,s) model of capital structure with an upper and a lower refinancing thresholds: when the actual debt is inside the thresholds the firm does not feel the need to change its capital structure. Despite model (12) is not a threshold model, its SOA grows with the actual-target leverage distance following the same economic intuition of Korteweg and Strebulaev (2012): the extent of the stimulus to change the actual leverage depends on how far companies' leverages are from the target.

The implementation of the KSS test is straightforward by computing a first-order Taylor series approximation to the ESTAR model under the null. In fact, the approximation leads to the classical ADF-like auxiliary regression (10), where we simply substitute the lagged and demeaned actual debt ratio regressor $L_{i t-1}-L_{i}^{*}$ with $\left(L_{i t-1}-L_{i}^{*}\right)^{3}$. The t-statistic of the estimate of the parameter of the latter cubic regressor (given the distribution tabulated in KSS) may be used to test for the unit root in the process generating the debt ratio. ${ }^{23}$

As with the BvD test, comparing outcomes of the ADF and the KSS tests provides the gain in power of the test with ESTAR nonlinearity under the alternative, which is measured by the share of firms classified as non stationary by ADF test and stationary under the KSS test: for these companies, the assumption of a SOA increasing with actual-target squared distance is crucial to understand the dynamics of the adjustment.

\section{3 - Case B1: non stationary TO determinants measured as broken targets}

Cases A1 and A2 above are alternative ways to model debt choices through linear or nonlinear SOA towards fixed debt targets assuming stationary of the $Z_{t}^{T O}$ TO determinants. The empirical literature on capital structure usually makes (without testing) this stationarity assumption, as it is required by the statistical properties of all models and approaches discussed in Section 2. In this stationary context, the failure to reject zero SOAs means that firms do not move towards the target, and that the PO/MT theory explains debt dynamics with a sequence of permanent shocks

\footnotetext{
${ }^{23}$ In the implementation of their procedure, in the case where the data has nonzero mean, KSS suggest to use demeaned data, i.e. to estimate the target debt ratio with the sample mean. For a similar non-linear approach applied to a heterogeneous panel of UK companies' debt ratios, see Ioannidis et al. (2003).
} 
$\varepsilon_{t}^{P O / M T}$ measuring the need for external funds and/or the timing of the equity market. However, if $Z_{t}^{T O}$ is not stationary, the non rejection of the null under the invalid assumption of stationary $Z_{t}^{T O}$ does not necessarily invalidate the TO theory.

Since the seminal work by Nelson and Plosser (1982), the univariate representation of many time series have been found to be characterized by stochastic non-stationarity. Non stationary patterns of debt ratios could be due to few (one or two) relevant events occurring during the life of the firm, rather than to unit roots (Perron, 1989). ${ }^{24}$ If we assume for simplicity that just one fundamental shock occurs at time $T B_{1 i}$, the debt ratios dynamics can be decomposed in a sequence of transitory PO/MT and TO shocks, as the AR models (8), plus a permanent effect of the event in $T B_{1 i}$ that can be modeled and estimated as a deterministic shift in the debt targets. If this is the case, the specification of model (10) must account for such target shift by using impulse and step dummy variables.

We exploit the innovational outlier models to test for unit roots against leverage stationarity with one (Perron and Vogelsang (1992)) and two (Clemente et al. (1998)) breaks. In particular, the AR model with gradual change after one break over the sample period (the innovational outlier model of Perron and Vogelsang (1992)) is specified as:

$$
\Delta L_{i t}=\mu_{i}+\delta_{1 i} D T B_{1 i t}+d_{1 i} D U_{1 i t}+\alpha_{i} L_{i t-1}+\sum_{j=1}^{p_{i}} \lambda_{i j} \Delta L_{i t-j}+v_{i t}
$$

while the corresponding model with two breaks (Clemente et al. (1998)) is:

$$
\begin{gathered}
\Delta L_{i t}=\mu_{i}+\delta_{1 i} D T B_{1 i t}+\delta_{2 i} D T B_{2 i t}+d_{1 i} D U_{1 i t}+d_{2 i} D U_{2 i t}+ \\
\alpha_{i} L_{i t-1}+\sum_{j=1}^{p_{i}} \lambda_{i j} \Delta L_{i t-j}+v_{i t}
\end{gathered}
$$

where $T B_{k i}(k=1,2)$ denote the year of the first $(k=1)$ and of the second $(k=2)$ break; DTB ${ }_{k i t}(k=1$, 2) is a pulse variable that takes the value 1 if $t=T B_{k i}+1$ and 0 otherwise; and $D U_{k i t}=1$ if $t>$ $T B_{k i}(k=1,2)$ and 0 otherwise.

Since the time in which the $\operatorname{break}(\mathrm{s})$ occurs is a priori unknown, parameters' estimation of models (13)-(14) is implemented as a sequential procedure run over the full sample, with dummy variables for each possible break date(s). The break date is found where the evidence is least favorable for the unit root null. Given the estimate(s) of the break date(s), if we reject the null $\alpha_{i}=$ 0 of unit roots in either model (13) or (14), we find evidence supporting a stationary model with

\footnotetext{
${ }^{24}$ Note that with long spans of data there is more chance to include at least one of such major events which can be considered as an exogenous outlier.
} 
breaking $L_{i t}^{*}$ driven by not modeled TO determinants. In the case of one break, the target leverage shifts from $L_{i}^{*}=\frac{\mu_{i}}{-\alpha_{i}}$ up to the break date $T B_{1 i}$ to $L_{i}^{*}=\frac{\mu_{i}+d_{1 i}}{-\alpha_{i}}$ afterwards.

If we ignore the occurrence of such shift(s), inferences based on constant-target models (as in cases A1 and A2 above) would fail to reject the null, and would erroneously support the dominance of the PO/MT theory (see the up-right quadrant of Table 1).

\section{4 - Case B2: non stationary TO determinants measured as debt averages by group}

A large portion of the empirical literature estimates the parameters of the pooled-linear model (3) by allowing for time dummies $\tau_{t}$. Usually, time dummies are motivated by the need to account for a degree of dependency across individuals due to collectively significant but unobservable effects, such as widespread optimism or pessimism. The use of time dummies is strictly related with the practice of data demeaning (see Appendix A2), and this fact allows for the introduction of another simple heterogeneous model.

Lev (1969) estimates heterogeneous linear models by assuming that firms adjust their financial ratios to predetermined ratios, based on industry-wide averages (in symbols: $L_{s t}^{*}=\frac{1}{N_{s}} \sum_{i=1}^{N_{s}} L_{i t}$, where $s=1,2, \ldots S$ denotes different industries and $N_{s}$ is the number of firms belonging to sector $s$ ). Lev's idea is shared by other works in which sectorial debt ratio averages (usually medians) are added to the list of the explanatory variables of the target, see e.g. Fama and French (2002), Hovakimian et al. (2001), Hovakimian (2006), Flanney and Rangan (2006), Lemmon et al. (2008), and de Jong et al. (2011).

If we assume that data of model (9) are demeaned using debt ratio averages by some grouping variable $g$ (i.e. $L_{i t}^{d}=L_{i t}-\frac{1}{N_{g}} \sum_{i=1}^{N_{g}} L_{i t}$, where $g=1,2, \ldots G$ ) we have:

$$
\Delta L_{i t}^{d}=\alpha_{i} L_{i t-1}^{d}+\mu_{i}+e_{i t}
$$

and the linear heterogeneous model:

$$
\Delta L_{i t}=\alpha_{i}\left(L_{i t-1}-L_{g t-1}\right)+\mu_{i}+\Delta L_{g t}+e_{i t}
$$

where - besides the individual effects $\mu_{i}$ - the target debt heterogeneity is also explained by the pattern over time of the groups' averages (in symbols $L_{i t}^{*}=\frac{\mu_{i}}{-\alpha_{i}}+L_{g t}$ ). Equation (16) measures, in brackets, the discrepancy between each debt ratio and its group average. In this new context, we can 
drop the assumption of stationarity of the pecking order determinants of the debt target by replacing it with the assumption of the relevance of average (possibly non stationary) targets by group in explaining the actual debt in the long run. ${ }^{25}$ Under the latter assumption, the stationarity or not of the time series averages is irrelevant for the interpretation of the test results.

While approaches presented in previous sections are not affected by the sample composition, this new test is based on some categorical (selection) variable used to classify firms into $g$ groups. The corresponding debt ratio averages (weighted or not-weighted means, or medians) become the driving forces of the heterogeneous firms' targets in the long run; hence the selection variable must be relevant for differentiating the sub-samples.

Lev (1969, Table 1), in the heterogeneous context with $\mathrm{N}=245$ observations over the period 1947-1966, finds that equity to total debt ratios reverts to industries arithmetic means in very few cases: the third quartile (ninth decile) of the SOA's estimates distribution (with sign reversed) is equal to $0.42(0.65)$ with t-statistics equal to $2.30(2.94) .{ }^{26}$ This lack of reversion in the heterogeneous context is supported by MacKay and Phillips (2005), who estimate a pooled regression for total debt/assets ratios against their industry medians (2-digit SIC level): the very slow-reversion SOA estimate of -0.032 is hardly significant despite being pooled. ${ }^{27}$

\section{5 - Case C1: non-stationary TO targets measured by heterogeneous cointegration relationships}

In this Section we estimate the SOA heterogeneous parameters using the dynamic model (6) in which - as above - we substitute the PO/MT determinants $X_{i t}^{P O / M T}$ with their univariate representation $a_{i}(L) X_{i t}^{P O / M T}=\varepsilon_{i t}^{P O / M T}$, but we do not make any assumption regarding the data generation process of the TO determinants $Z_{i t}^{T O}$. Therefore, $Z_{i t}^{T O}$ must be measured with variables (selected on the basis of the TO theory) that are explanatory in the dynamic specification of debt ratios as an equilibrium-correction model $(\mathrm{EqCM})$ :

$$
\Delta L_{i t}=\alpha_{i}\left(L_{i t-1}-\beta_{i} Z_{i t-1}^{T O}\right)+\mu_{i}+e_{i t}
$$

\footnotetext{
${ }^{25}$ For example, the industry (group) median leverage is one of the alternative measures exploited by D'Mello and Farhat (2008) to proxy the time-varying optimal (target) debt ratio. Other measures are the firm's time-series mean leverage (as discussed in cases A1 and A2 in Sections 3.1 and 3.2) and the leverage ratio predicted from cross-sectional regressions.

${ }^{26}$ Note that Lev (1969) model specification defines reverted-signs SOAs, i.e. that the speed of adjustment is expected to be positive. Accordingly, the critical value at 5\% (10\%) of the Dickey-Fuller statistic distribution is 3.0 (2.63) when $T=20$, as in the Lev's sample.

${ }^{27}$ These findings against the relevance of the role played by industry determinants in explaining capital structure are also supported by Kayo and Kimura (2011) who use a statistical multilevel approach: time- and firm-level determinants explain $78 \%$ of leverage, the rest is left to less relevant industry- and country- determinants.
} 
where errors $e_{i t}$ combine the distributed lags of PO/MT random shocks $\varepsilon_{i t}^{P O / M T}$ with the actual debt shocks $\varepsilon_{i t}: e_{i t}=\gamma_{i} \frac{\varepsilon_{i t}^{P O / M T}}{a_{i}(L)}+\varepsilon_{i t}$. Given that $e_{i t}$ are autocorrelated, the dynamics of model (17) must be augmented with $p_{i}$ lags of the dependent variable $\Delta L_{i t}$ in order to reach iid errors $v_{i t}$ :

$$
\Delta L_{i t}=\alpha_{i}\left(L_{i t-1}-\beta_{i} Z_{i t-1}^{T O}\right)+\mu_{i}+\sum_{j=1}^{p_{i}} \lambda_{i j} \Delta L_{i t-j}+v_{i t}
$$

Although simple, model (18) is less parsimonious than model (10). The explicit presence of $Z_{i t}^{T O}$ among the regressors makes it possible to estimate the long-run target without assuming neither the stationarity of $Z_{i t}^{T O}$ (as in cases A1 and A2 above), nor the existence of breaking targets (case B1) or the driving effect of industry-wide averages (case B2). Here, the time varying target leverage is conditional on $Z_{i t}^{T O}$ :

$$
L_{i t}^{*}=\beta_{i} Z_{i t}^{T O}+\frac{\mu_{i}}{-\alpha_{i}}
$$

The actual-target debt discrepancy $L_{i t}-L_{i t}^{*}$ is always stationary if firms follow the TO. In fact we have two possibilities: (1) when the variables in $Z_{i t}^{T O}$ are stationary, both the actual debt $L_{i t}$ and the target $L_{i t}^{*}$ are stationary (and consequently their discrepancy too); (2) under non stationary $Z_{i t}^{T O}, L_{i t}$ and $L_{i t}^{*}$ deviations can be only temporary, as the two non-stationary variables must share under valid TO - one or more common stochastic trends; in statistical jargon, $L_{i t}$ and $Z_{i t}^{T O}$ are cointegrated. The cointegration between $L_{i t}$ and $Z_{i t}^{T O}$ variables can be tested with alternative approaches, which can lead to not equivalent outcomes as they focus on different statistical characterizations of the non-cointegration (see Gregory et al. (2004)). Monte Carlo experiments usually show that no one cointegration test is found to dominate the others in terms of size and power in finite sample sizes (Gonzalo and Lee (1998)). Therefore, we will inspect the results coming from three different cointegration approaches

The first is the Engle and Granger (1987), henceforth EG, cointegration test, which is based on the direct assessment of the stationarity of $L_{i t}-L_{i t}^{*}$ deviations with a Dickey-Fuller type test, where $L_{i t}^{*}$ is proxied by the fit of the OLS regression of $L_{i t}$ against $Z_{i t}^{T O}$. Under the EG approach, we run static regressions like:

$$
L_{i t}=\beta_{i} Z_{i t}^{T O}+c_{i}+u_{i t}
$$


which represent the heterogeneous counterpart of the pooled linear models, $\beta=\beta_{i} \forall i$, for the target usually employed by the literature. In particular, three remarkable differences with the pooled literature emerge: (1) the static long run regression (20) is fully heterogeneous, as it is estimated firm by firm; (2) the significance of $\beta_{i}$ parameters (the significance of the TO effects in shaping the target leverage) is assessed by testing the stationarity of the residuals $\widehat{u}_{i t}=L_{i t}-\left(\widehat{\beta}_{i} Z_{i t}^{T O}+\widehat{c}_{i}\right)$ with suitable statistical distributions, to prevent the spurious significance that could arise from standard t statistics (Granger and Newbold (1974)); (3) under cointegration, OLS estimators of equation (20) are super-consistent, i.e. not affected either by $Z_{i t}^{T O}$ endogeneity or omitted dynamics, see Stock (1987). The drawbacks of the EG approach are: the disequilibria $L_{i t}-L_{i t}^{*}$ is assumed to feedback only to debt changes, and not to $Z_{i t}^{T O}$ (this is the so called "weak exogeneity" of $Z_{i t}^{T O}$ ); a common factor restriction is imposed to the dynamics of the relationship between debt and TO determinants.

The EG common factor restriction is relaxed in the second cointegration approach we follow, that of Boswijk (1994), henceforth BO, and of Banerjee et al. (1998), henceforth BA. They base their cointegration tests on the OLS estimate of this dynamic relationship:

$$
\Delta L_{i t}=\alpha_{i} L_{i t-1}+\gamma_{i} Z_{i t-1}^{T O}+\mu_{i}+\sum_{j=1}^{p_{i}}\left(\lambda_{i j} \Delta L_{i t-j}+\omega_{i j} \Delta Z_{i t-j}^{T O}\right)+v_{i t}
$$

where the dynamics of $Z_{i t}^{T O}$ is added to equation (18), so that $\gamma_{i}=-\alpha_{i} \beta_{i}$. In particular, BA cointegration test is the t-statistic on the null hypothesis $\alpha_{i}=0$, whereas BO cointegration test is based on the Wald F-statistic testing the joint null hypothesis $\alpha_{i}=\gamma_{i}=0$. Under both null hypotheses of no-cointegration, the distributions of t- and F-statistics are not standard and specific critical values must be used. Although apparently quite close to model (3), equation (21) not only introduces heterogeneity, but also acknowledges that non-standard $\mathrm{t}$ and $\mathrm{F}$ distributions are more appropriate when variables are persistent (see Hall et al. (1992)).

In order to relax the weak exogeneity assumption for $Z_{i t}^{T O}$, still present in both BA and BO tests, we refer, as the third cointegration test, to the Johansen (1995) approach, JO henceforth. The JO test is the test on the rank $r$ of the matrix $\Pi$ deriving from a vector autoregression (VAR) model parameterized as a vector error correction mechanism (VECM):

$$
\Delta X_{t}=\Gamma_{0}+\sum_{k=1}^{p-1} \Gamma_{k} \Delta X_{t-k}+\Pi X_{t-1}+\varepsilon_{t}
$$


where $X$ is the vector of all the variables explained by the system ( $L_{i t}$ and $Z_{i t}^{T O}$ ), and $r$ is the number of cointegration relationships among the variables in $X$. The significance of $Z_{i t}^{T O}$ in driving the long run debt target needs that $r>0$.

Even though the JO approach is more general than EG, BA and BO approaches, it presents some pitfalls. First, being VAR-based, JO entails a larger number of parameters to be estimated than that of the other single-equation approaches; as said, this can be a severe limitation in our context. Second, the cointegration rank can be inflated by the presence of stationary variables in the system: besides genuine cointegrated relationships between non stationary variables, some stationary company ratios might be combined with intercepts leading to a stationary steady state. Finally, if the non-stationary variables have a VAR representation with a near-singular covariance matrix, JO tends to find spurious cointegration.

\section{Empirical results}

Our panel data is drawn from Compustat for the period 1950-2011. Cleaning rules, depicted in Appendix A3, leads to a strongly unbalanced panel. In order to maximize the number of time observations $T$ by company, we extract alternative balanced sub-panels by selecting only those firms belonging without interruptions to alternative time spans, from the longer 1950-2011 to the shorter one 1990-2011. Accordingly, the number $N$ of firms of each balanced sub-panel decreases with the length of the span (from about 400 for the shorter one to 50 for the longer). Note that the firms belonging to a given-span sub-panel are by definition included in all the shorter-span panels. To assess the robustness of our findings, we provide results over seven alternative sub-panels with decreasing $T$ and increasing $N$ (details are e.g. in the first column of Table 2)

\section{1 - To what extent and at what speed debt ratios revert to deterministic targets?}

We summarize the outcome of all the heterogeneous models introduced in Section 3 by computing the shares of companies which display significant reversion rates of their actual debt ratios towards the target against those which do not revert. We also average and compare the SOAs of reverting and of non-reverting firms. As suggested in Pesaran and Smith (1995) and Pesaran et al. (1999), SOA mean group estimates for the two different groups of reverting and not-reverting firms offer consistent estimates of aggregate SOAs, independently on being SOA parameters poolable or not. Of course, the larger the difference between the two average estimates, the less likely the poolability assumptions. 
Although the company targets depend on alternative test procedures, in this section we focus only on those models assuming that debt targets are implicit in the deterministic components of the various univariate models or come from specific correlations across idiosyncratic shocks, as described in cases A and B of Section 3.

Main results are in Table 2. The upper panel of Table 2 refers to the short-term debt ratio, the middle panel to the long-term ratio, and the lower panel to the total debt ratio (i.e. the sum of the previous two). The outcomes along the columns refer to alternative testing procedures. It is worth remembering that, more or less implicitly, the mainstream literature assumes the stationarity of the leverage, i.e. that the shares in Table 2 are very close to one.

\section{Table 2 here}

The first two columns - labeled as "ADF" and "DFGLS" - report the shares in each balanced panel of companies which revert over time to constant and heterogeneous targets according to linear models. Both tests suggest that the share of reverting firms is clearly below one, around $50 \%$ and $20 \%$ in the case of short-term and long-term debt respectively. The shares for the total debt range only slightly above those for the long term debt (about 25-30\%); this result can be expected, given that long-term debt represents, on average, about the $70 \%$ of total debt.

The subsequent five columns of Table 2 refer to the issue of target reverting with asymmetric and non linear models. The "BvD" column reports the share of target-reverting firms with asymmetric speeds of adjustment. With respect to the case of linear models, this share goes up to about $60-70 \%$ for the short term and to $25-30 \%$ for the long term debt: there is a portion of firms for which the assumption of an asymmetric adjustment is crucial to detect a reverting behavior (remember the upper-right cell in Table 1). Interestingly, almost all (about 98\%) the mean-reverting firms have higher (or at worst not lower) SOAs when they are over-levered in their short-term debts as if being above the target for this kind of debt would imply costs markedly higher than those related to being below the target. This asymmetry is reversed in the case of the long term debt

Quite reasonably, the longer the available time span the more likely detection of significant asymmetries, given that, in the context of heterogeneity, the finding of such asymmetric behaviors needs fairly long spans of observations. Oppositely, the pooling literature uses unbalanced panels with quite shorter than ours average $T$ and, in this way, finds results which depend more on the cross-section variability (i.e. on the poolability assumption) than on the single-firms' pattern over time. 
When non-linearity is measured through SOAs with ESTAR dynamics ("KSS" column) the shares of mean reverting firms are in line with those delivered by the linear models, also because of the inefficiency of the KSS approach. ${ }^{28}$

In the next three columns, we allow the linear model to adjust with respect to a breaking rather than constant - target. The shares go further up: the short term debt reverts for about $70 \%$ of the cases (in the large majority of them only one break in the target is needed), while the long term debt reaches shares around $35-40 \%$ and equally relies on models with one or two breaks in the target. This fact could suggest that the (unknown at this stage) determinants of target leverage could be quite persistent over time, and that in the present context breaks in target can proxy for its long and persistent waves. Given that this effect is by far more relevant for longer term debt, persistence in debt shocks seems to affect more this form of financing.

Finally, the last two columns of Table 2 report the shares of firms whose ratios revert towards the mean and median industry leverage respectively. ${ }^{29}$ Results - obtained by running ADF tests on demeaned data - are in line with those obtained with simple linear models and agree with the findings in Lev (1969): the pattern of the industry averages over time does not drive, alone, the leverage of the companies belonging to that sector. This result is at odds with Frank and Goyal (2009) who, in a pooled context, claim that the median industry is empirically the single most powerful factor in explaining debt ratios. While our finding is also consistent with Hovakimian et al. (2001) who claim that their outcomes do not change when models are estimated with or without demeaning data.

Overall, results in Table 2 are quite clear cut: regarding the total debt ratios, the shares of target-reverting firms are always well below $40 \%$, independently on the test used (i.e. on the definition of the target). This fact leads to two main broad considerations: 1 . the econometric methods used in the literature to estimate SOAs are at least questionable, as they are broadly based on data in prevalence unfit to their statistical assumptions; 2. heterogeneity matters, because poolability would entail shares equal either to zero (when all firms are non reverting) or to one (when all firms are target reverting, although in this case poolability would also require the same SOA for all the companies) while the estimates in Table 2 are never close to their upper and lower limits. $^{30}$

\footnotetext{
${ }^{28}$ Given its data-intensive aspect, the KSS dynamics has not been estimated for the shorter 1990-2011 span.

${ }^{29}$ The 12-industry disaggregation used to compute sectorial averages is that downloadable from Kenneth French website: http://mba.tuck.dartmouth.edu/pages/faculty/ken.french/ftp/Industry_Definitions.zip. To allow for enough data in each cell, the averages are computed over the whole unbalanced panel. In this way, we expect that these averages better represent the by-industry patterns for the US economy (see Table A3.1). Results, available upon request, are robust to the use specific averages by sub-panels.

${ }^{30}$ Following Pesaran (2012), we checked for the robustness of the finding of shares of reverting firms higher than zero by using the panel unit root tests of Im et al. (2003) and of Pesaran (2007). The null hypothesis is strongly rejected in all
} 
In particular, the target reversion behavior is largely more likely for the short-term debt, leading to the presumption that this financing form is less affected by adjustment costs. On the contrary, the long-term debt seems more driven by PO considerations: the needs of financing investment, that is an activity usually requiring more than one year, has a greater impact on the long-term debt; the possibly random changes in the cash flow deficit impart persistent shocks to the historical leverage pattern.

The latter point is deepened in Table 3, where averages of SOA estimates (the unbiased mean group estimators, MG) are computed for reverting and not-reverting firms; the structure of Table 3 is quite similar to that of Table 2 .

\section{Table 3 here}

The average SOA estimates for the group of non target-reverting firms in both short- and long-term debt ratios is much lower (less than one-third) than those of all the other estimates referring to mean-reverting firms. Two interesting facts emerge in comparison with the empirical literature: 1.the average SOA estimates of not reverting firms are in line with those obtained from pooled models under the assumption of stationary; 2. the average SOA estimates of reverting firms are, instead, in line with those reported in Frank and Shen (2014) who assume time varying targets as heterogeneous functions of a high number of determinants. We can conclude that pooled SOA estimates (sometimes labeled as "snail's pace") is an upward-biased estimate of a speed of adjustment that in the population is often zero. At the firm-level, it is important to consider timevarying, rather than static, leverage targets.

Linear SOA estimates are higher for the short-term debt than for the long-term debt: this confirms the reasonable hypothesis of less costly and easier adjustments for the short-term financing. When we use sub-panels with shorter time spans this difference tends to vanish, and the average SOA for both debt-ratios converge towards a broad estimate of -0.7/-0.8: about the 70-80\% of the discrepancy between actual and desired (target) debt ratios is closed in the following year. This quite high speed is even larger if we consider estimates based on asymmetric dynamics or shifts.

From Table 2 (column "+>-") we know that, especially for short term debt, the most frequent adjustment is that of firms which react more to the actual-target gap when over-levered. The two

sub-panels under different assumptions about de-meaning or not of the data, and about the nature of firms' shocks heteroscedasticity and cross-correlation. The outcome that a portion of firms is target-reverting has been also found in Peel et al. (2004) for the UK, Bontempi and Golinelli (2012) for Italy, and Yang et al. (2014) for Taiwan and China. Symmetrically, shares of reverting firms "significantly" smaller than one are supported by the clear rejection of Hadry (2000) heterogeneous panel stationarity test. Results are available upon request. 
columns under the label " $\widehat{\alpha}_{i}^{+}<\widehat{\alpha}_{i}^{-}$" report the average SOA estimates for these firms, with $\widehat{\alpha}_{i}^{+}\left(\hat{\alpha}_{i}^{-}\right)$ being the estimated speed of closing the gap when these firms are over-levered (under-levered). Analogously, the two columns under the label " $\widehat{\alpha}_{i}^{+}>\widehat{\alpha}_{i}^{-}$" report the average SOA estimates for the firms which react more to the actual-target gap when under-levered (column "+<-" of Table 2), with $\hat{\alpha}_{i}^{+}\left(\hat{\alpha}_{i}^{-}\right)$being the estimated speed of closing the gap when these firms are over-levered (underlevered). SOAs close to -1 mean that gaps are closed after one year, while SOAs above -1 (for example -1.2) indicate that firms overshoot the target. Hence, estimated SOAs show that the overshooting dynamics pushes the firms, when over-levered, below the target in less than one year, while the process of climbing up towards the target is quite slow for firms in under-levered state as they act if were waiting for positive shocks. When the estimates of $\hat{\alpha}_{i}^{+}$and $\hat{\alpha}_{i}^{-}$are not significantly different, the target-reverting process needs just a single SOA that, as expected, is very close to that estimated by the linear model.

Since the average SOA estimates cannot be computed for ESTAR models as they are nonlinear functions of the actual-target leverage gaps, Figure 1 plots two of these SOA functions which correspond to the first and third quartiles of the distribution of $\theta$ (in equation (12)) estimated for reverting firms over the period 1980-2001.

\section{Figure 1 here}

The wide distance between the two depicted patterns suggests large SOA heterogeneity when the size of the gap is about half of the average total debt ratio $( \pm 0.125)$, the two corresponding speeds range from -0.9 to -0.4 , i.e. from an adjustment process that closes $90 \%$ of the gap in about one year to another one that takes almost five years to close the same amount of gap.

Finally, when the target is proxied by a shifting process, SOAs are in general above -0.80 , suggesting that, independently on the term structure of debt, the $90 \%$ of the adjustment process is accomplished in slightly more than one year. Again, these SOAs estimated for firms reverting towards industry-level targets confirm that the adjustment process is more rapid than that estimated by pooled regressions.

\section{2 - Extending the models to targets driven by explicit explanatory variables}

We can extend the results above by switching from univariate to the multivariate approach of model (18). In order to empirically augment with regressors the univariate specification, the first step must be that of selecting the variables entering the set of TO determinants $Z_{i t}^{T O}$. To do so, we have to acknowledge that the assumption of parameters' heterogeneity is quite expensive in terms of number of parameters to be estimated with time series of $T$ observations. Therefore, in order to keep 
the model as much parsimonious as possible, we summarized the effect of TO determinants with four variables, on the basis of the most commonly used variables in literature: 1 . the net stock of all tangible assets; 2 . the internal cash flow; 3. the relative cost of capital; and 4. the non-debt tax shields. ${ }^{31}$ Details about their definition are in Appendix A3. Further, the number of parameters to be estimated is also kept low by choosing the lag order of both single-equation (21) and VAR models (22) with the parsimonious Schwarz's Bayesian information criterion.

The main results are reported in Table 4, which is broadly structured as Tables 2 and 3: its columns list both shares of firms reverting towards the debt target and average SOA estimates, while the rows detail results over alternative sub-periods. In order to ensure results' comparability, the companies entering each sub-panel are exactly the same as those in the previous section. However, the inclusion of other variables (the TO determinants), raises the issue of the completeness of their information set, as the alternative panels in sub-samples were balanced on the basis of the available data for debt ratios. For this, the column labeled as "incomplete" reports the share over the total of those firms for which we were not able to run the cointegration approaches of this section because of lacking of the data. ${ }^{32}$

\section{Table 4 here}

The next two columns respectively report the shares of the firms which do not revert to the (cointegrated) target and the complementary share of those firms which revert. The approach that we follow to classify our firms is that of Engle-Granger (EG), which can be seen as a sort of baseline method, whose parsimony is well known. Results are quite clear cut: the advantage of using explicit and potentially non-stationary determinants for debt targets, does not trade off the disadvantage of more parameters to be estimated, as the composition of reverting/not reverting firms is quite similar to that detected with univariate approaches. In other terms, the advantage of explaining the persistency of debt ratios with persistent TO explanatory variables is not really much relevant, as it is easily offset by the complexities induced by the multivariate setting we follow here. In addition, a number of previous findings remain qualitatively the same. The share of target reverting firms is larger if we focus on short term debt, and the corresponding average SOA estimates for the reverting companies in the last column of Table 4 are broadly in line with those obtained with breaking trends in Table 3.

\footnotetext{
${ }^{31}$ As with debt, all variables measuring levels are defined as ratios over the total assets.

${ }^{32}$ With this regards, note that the share of firms with incomplete data slightly grows in shorter $T$ samples, as the related increase in the number of firms is likely to select companies with lacking data.
} 
The intermediate three columns report alternative shares of reverting firms on the basis of the other three approaches listed in Section 3.5, namely Johansen ${ }^{33}$, Banerjee et al. and Boswijck that allow relaxing some of the Engle-Granger restrictive assumptions.

Overall, results are broadly in line with the univariate outcomes of the previous section probably because of the poor identification of reliable target drivers using few variables. ${ }^{34}$

The preliminary results of this section suggest that the use of the cointegration approach to explain very persistent leverage patterns with the inertia of few but potentially relevant TO determinants does not entail per se evidence of the relevance of such determinants to explain debt dynamics. This outcome, which is fully in line with the recent strand of critiques to the results of dynamic panel (pooled) estimates, emerges even more clearly with our heterogeneous approach based on cointegration tests.

The messages coming from these first results are twofold. First, it is not easy to find relevant drivers of debt targets, as the apparently statistical significance detected by much of the past studies was much more due to the poolability assumption rather than to genuine theoretical relevance. Second, the concept of SOA is founded on concepts related with model dynamics, and the deepening of time series methods can be very helpful to improve our knowledge about company financing choices.

Our findings can suggest some future directions of the applied research in this field. Based on these results, we can suggest two main developments: 1. to improve the use of the Johansen approach by supporting it with more preliminary data analyses to better characterize the statistical models for the TO explanatory variables; 2 . to enlarge the number of the TO determinants but at the same time keep low the number of variables in VAR models by exploiting the increased information set with few common factors. Without explicitly tackling cointegration and nonstationarity issues, the latter development has been recently introduced by Frank and Shen (2014) who acknowledge the need of better measures of time-varying targets.

\footnotetext{
${ }^{33}$ The implementation of the Johansen approach is based on the following stylized steps: the test for the cointegration rank is zero; under the non rejection of the null the company is classified as non reverting, if the null is rejected, we impose rank one and tested for loading parameters significantly negative in the debt equation; if the null is not rejected, we again classify the company as non reverting, under the alternative the company is classified as reverting towards a long run debt target.

${ }^{34}$ Similarly to the case of unit root tests, we can support the finding of larger-than-zero shares of firms whose leverage ratios are cointegrated with TO determinants by running the heterogeneous panel cointegration tests of Pedroni (1999) and Westerlund (2007). Results are again clear cut: Pedroni test statistics (with and without time dummies) always reject the null that all the firms in the panel are not related in the long run with the four explanatory variables used in this paper. The same outcome is delivered by Westerlund test (whose standard errors were bootstrapped to tackle the issue of the cross-correlation between debt ratio shocks) only for the short-run leverage ratios, while the null of no relationship between leverage and selected TO variables is never rejected for the long-run ratios.
} 


\section{3 - The stability of results over rolling windows}

Previous section showed that the shares of stationary firms in each sub-sample are significantly higher than zero and lower than one, i.e. that firms are significantly heterogeneous in their adjustment processes of leverage ratios towards targets. However, such analyses have been carried out over alternative samples of balanced panels of those firms that always belong to specific sub-periods. In this case, the variability of the results listed along the rows of Tables 2-4 is due to the joint effect of two factors: (a) the sample composition variability, because of the increase in the number $N$ of panels' members due to the decrease in the number of years $T$ in which firms have to report no-missing data; $(b)$ the time variability, because specific and different events can affect the behavior of firms over different time sub-periods.

The sample composition variability over alternative $T$-fixed samples is depicted in Figure 2 by four straight lines: each line counts $N$ (the number of firms) in the sub-period of time reported in its corresponding label. Conventionally, the horizontal axis reports the first year of the alternative sub-samples. Of course, the information in this axis is also reported in selected rows of the first column ("Begin") of Tables 2-4, and the information in the vertical axis is also reported in the third column ("Time span"), same rows. The sum of the "begin" year plus the labeled $T$ gives the "end" year of each subsample.

\section{Figure 2 here}

The time variability of counts is represented by the upper curve in Figure 2. Its pattern reports the number of Compustat firms belonging to a sequence of sub-samples with a rolling window of amplitude $T=27$ years. For example, the observation corresponding to "60" on the horizontal axis measures the number of firms $(N=356)$ always in the sample over the period 1960-1986, and the following observation $(N=345)$ is the number of firms belonging to the 1961-1987 sub-period.

Over the period 1960-2011, 97 firms always belong to all rolling samples above because they have no missing data from 1960 to the end of the whole sample (2011). The balancing of the panel over the 1970-2011 period adds further 64 new firms which entered Compustat from 1961 to 1970 and then never dropped out. The reduction of other 5 years of the sub-sample further increases the balanced 1975-2011 sub-panel of other 35 new firms. The entry of other 31 new firms occurred during the five years from 1976 to 1980 , for a total of $N=227$ firms belonging to the 1980-2011 balanced panel. ${ }^{35}$ The story told by the upper curve is quite different, as the time series of counts is

\footnotetext{
${ }^{35}$ The latter count $N=227$ is obtained by summing the number of firms always in the data-set from 1960 to 2011 (97) plus the three changes mentioned in the text (i.e. $64+35+31$ ). Two points are noticeable: (1) the increased number of firms is due to new companies in the sample which never drop out in the following years, up to 2011 ; $(2)$ the rate at which firms enter the sequence of sub-samples is approximately the same, i.e. about 65 new firms every ten years.
} 
the annual balance of the entry of new firms net of those firms which exit (did not survived) each year, plus of course the firms always belonging to the two consecutive rolling subsamples. As a result, the average level of the rolling sample, about 300/350 firms by year, is much larger than that of the balanced samples. Therefore, both shares and mean-group SOA averages are better estimated here than in previous sections.

In addition, given that the rolling sub-samples analyzed in this section are affected more by events occurring over time rather than by sample composition, the fluctuations in the rolling estimates are more due to models' parameter instability over time.

The four graphs in Figure 3 show the shares of reverting firms (upper panel) and the average SOAs (lower panel) over rolling samples of 27 years beginning in the years reported along the $\mathrm{x}$ axes. The left side columns pertain to short-term debt, the right side ones to long-term debt.

\section{Figure 3 here}

The upper panel graphs compare the outcomes in terms of alternative shares of reverting firms for short- and long-term debt. As noted in previous sections, the shares relating to short-term debt are markedly higher than those relating to long-term always in rolling samples. Further, the shares show a slight tendency to increase since mid-1970s, and the asymmetric adjustment and breaking target models deliver shares of short-term debt reverting firms which are higher than those of the other three models, while in the long-term debt case only breaking targets shares seem slightly higher. In both cases, the study of the cointegration between debt and specific determinants does not modify the basic outcomes.

The lower panel compares alternative rolling SOA estimates. They all are remarkably stable over time, and suggest that debt targeting firms broadly revert to their optimal levels in around onetwo years, independently of whether short- or long-term debt. It is worth stressing again that - in general - the estimates of average speeds for the target-adjusting firms are again greatly higher than those usually reported in studies assuming poolability.

\section{Concluding remarks}

In this paper, a novel and very simple approach has been introduced to inspect the dynamics of companies' leverage ratios, based on the explicit acknowledgment of two well known stylized facts: 1. firms are potentially heterogeneous in their speed of adjustment because they face different constraints in adjusting towards their leverage optimal targets; 2. actual leverage ratios fluctuations over time are very persistent. The novelty here is not methodological because our tools are based on consolidated unit root and cointegration tests, but our contribution stands in the use of these 
techniques in assessing the target-reversion of leverage ratio fluctuations through the lens of fully heterogeneous models. In this, our models make a good job in further improving the understanding of data features that previous models cannot, as we are able to explain much of the results of the empirical literature on leverage dynamics and suggest focusing in few issues.

We provide evidence that the existence of a dynamic process of actual debt adjustment towards the target, as suggested by the Trade-off theories (TO) of capital structure, is not necessarily the rule. In fact, when we consider the most favorable case of the short-term leverage ratio, the share of firms which behave following the TO theories - about $60-70 \%$ - is never even close to levels which could support the stationarity assumption. This share dramatically drops to about one-quarter in the case of the long-term leverage ratio. Given the prevalence of the latter form of financing, only about $30-35 \%$ of firms in our sample have total debt ratios which revert towards their leverage targets, independently on the way the alternative models here proxy the target.

This outcome trace the causes of the most awkward results of the literature on empirical capital structure (see e.g. Chang and Dasgupta, 2009, and Hovakimian and Li, 2011) and give a new interpretation of the acknowledged low SOA estimates usually reported in the empirical research (see e.g. Fama and French, 2002, Flannery and Rangan, 2006, and Iliev and Welch, 2010). The invalidity of the maintained hypothesis of SOA parameter poolability biases its estimates, and with leverages generated by non stationary processes the usual significance tests are invalid. In other terms, firms' behavior is too much heterogeneous to be summarized by pooled parameters, and the practice of exploiting this bulk of heterogeneity through the ex ante imposition of ad hoc variables cannot be statistically rejected by data independently on their usefulness.

Therefore, any statistically sounded method of inference about firms' financing behavior should better start from parsimonious models of unconstrained-heterogeneity and, only afterwards, assess the ability of alternative measures of the theoretical determinants to explain such heterogeneity in the multivariate context. Unfortunately, the preliminary cointegration results obtained here are not much encouraging, as the inclusion in the model of heterogeneous target drivers (TO determinants) leads to results that do not substantially differ from the ones we obtain with univariate unit root tests.

This lack of cointegration, i.e. of a statistically founded long run relationship between target leverage and some TO variables, for a significant portion of companies can be explained by the well known difficulty (see among others Lemmon et al. 2008) of measuring the wide range of theoretical TO determinants with few variables. Very recently, Frank and Shen (2014) have introduced the common factors approach to summarize, with few heterogeneous factors, a wide information set of 
146 variables which likely encompasses the TO unobservable determinants, and their results show a substantial increase of firms' SOA which is in line with our evidence.

Merging these results will lead to the future challenges of the empirical capital structure literature: heterogeneity matters and the genuine TO determinants are difficult to capture with few explicit variables. A promising approach to explain leverage fluctuations could be based on the core concept of persistence: we must find, using heterogeneous cointegration tools, the few variables that genuinely explain the persistent waves of leverage, rather than looking for statistically significant effects that, with so much persistence, may be simply spurious. 


\section{Appendix A1 - Issues in modeling pooled capital structure dynamics}

\section{A1.1 - Theoretical determinants and the corresponding measurements}

The empirical relevance of PO/MT and TO determinants in explaining firms' debt choices is not only based on a number of theoretical assumptions, but is also supported by survey evidence. ${ }^{36}$ However, the big issue of measuring the explanatory variables of the general model (1) is still not settled in a satisfying way. Frank and Goyal (2009) report a long list of empirical proxies of PO/MT and TO theoretical variables which are used in empirical works, i.e. which can enter in $X$ and/or $Z$ vectors. Even excluding the most strongly correlated measures belonging to the same block of determinants, they list 25 explanatory variables. However, among the others, Lemmon et al. (2008) point to the difficulty of measuring the wide range of TO determinants with few relevant variables.

\section{A1.2 - Adjustment costs and slow pooled SOA estimates}

Some papers (see the recent Graham and Leary (2011)) acknowledge that testing capital structure adjustments for the whole economy through the linear model (3) - as it is usually done in the literature - has limited informative value since it is assumed that all firms have the same adjustment costs. ${ }^{37}$ As an alternative, some authors compare the estimation results coming from subsamples of firms, with potentially different adjustment costs. However, the ex ante selection/definition of subsamples cannot prevent results from being affected by an invalid poolability assumption of SOAs.

As documented by Flannery and Watson Hankins (2013), in the recent econometric practice for capital structure, within or first-difference transformations of model (3) are employed to get rid of the individual effects $\mu_{i}$. The resulting large information sets made of firm-year observations are exploited by either OLS or GMM estimators under the assumptions of data stationarity and slope parameters poolability. Even more recently, Elsas and Florysiak (2014) extend Flannery and Watson Hankins (2013) results to account for the fractional nature of the dependent variable and, in doing so, they introduce a new pooled estimator for data assumed to be stationary.

The large amount of available variability, thanks to thousands observations used to estimate few pooled parameters, leads to very precise estimates of $\gamma, \alpha$, and $\beta$; small standard errors

\footnotetext{
${ }^{36}$ See Graham and Harvey (2001) for the US, and Brounen et al. (2006) for some European countries.

${ }^{37}$ Leary and Roberts (2005) show that firms' financing behavior is consistent with the presence of adjustment costs, and companies actively rebalance their leverages to stay within an optimal range. In this context, the persistency of leverage's shocks (low SOAs) emerging from linear models is more likely due to high adjustment costs than to indifference towards the target. On the other side, Titman and Tsyplakov (2007) note that a number of findings are inconsistent with models based solely on adjustment costs. The reason, they argue, is that both target leverage and SOA are affected by an extended list of interacting determinants, besides adjustment costs, which can be firm specific. We face this point in Section 3.
} 
unavoidably inflate the SOA statistical significance. ${ }^{38}$ The precision/significance of SOA estimates is usually interpreted as supporting the linear dynamic model (3), and not much attention is paid to consider that SOA point estimates - usually ranging between -0.15/-0.35 - suggest amazingly slow speeds of adjustment: with a SOA estimate of -0.25 we are saying that all firms in the sample bridge $90 \%$ of the gap between actual and target debt within the space of about 8 years. ${ }^{39}$ Fama and French (2002, p. 24) label such low rates of mean reversion as "snail's pace", and Welch (2004, p. 129) talk about "practically no-readjustment". Of course, these unconvincing results stimulated a strand of literature to revisit model (3) to measure more reliable SOAs.

\section{A1.3 - The awkward interpretation of significant adjusting mechanisms}

Since Shyam-Sunder and Myers (1999, section 4.4), it has been noted that the explanatory variables driving TO debt targets are presumably related to firms' characteristics. If this is true, also firms' leverage is related to individual characteristics, and this independently on being generated by an optimization exercise. As a consequence, the correlation of leverage with its target determinants does not necessarily corroborate the validity of the prediction of the TO theory. ${ }^{40}$ Chang and Dasgupta (2009) show that Shyam-Sunder and Myers (1999) results can be replicated by using simulated data for leverage, generated as being unrelated with any target. Also Hovakimian and $\mathrm{Li}$ (2011) show that models like equation (3) produce results severely biased in favor of the target adjustment, and list a number of good practices - such as the use of recursive two-step estimation methods and the exclusion of firms characterized by extremely high debt ratios - useful to estimate dynamic models with better power properties

\section{A1.4 - Neglected unit roots and cointegration}

From the statistical point of view, much of the problems listed in issues \#2 and \#3 can be explained in the light of spurious co-trending literature (see e.g. Granger and Newbold (1974)): if actual leverage $L$ and some PO determinants $Z$ in model (3) are strongly persistent (i.e. characterized by stochastic trends), the statistical significance of SOAs cannot be assessed by using

\footnotetext{
${ }^{38}$ Iliev and Welch $(2010$, p. 2) say that "Ironically, the main challenge in this literature could be viewed as not too much, but too little estimation uncertainty". We believe that our approach can tackle this challenge.

${ }^{39}$ The misunderstanding of the literature assuming poolability is well represented by quotes like this: "A SOA coefficient estimate of $25 \%$ [i.e. $\alpha=-0.25$ in model (3)] means that it takes the average firm 2.4 years to recover half of the target leverage deviation [...].", Eckbo and Kisser (2014, note 2). Actually, the a priori assumption of SOA poolability implies that it is not the average firm but every firm in the sample to react so slowly.

${ }^{40}$ Chen and Zhao (2007) go further and explicitly talk about the mechanical mean reversion of leverage ratios. In short, they claim that debt ratios revert towards the mean simply because they are ratios, and not because they are pushed by TO-like behaviors. In order to prevent this issue, sometimes authors exclude from the sample ratios smaller than $10 \%$ and higher than 90\% (see e.g. Warr et al. (2012)), and Elsas and Florysiak (2014) suggest a new estimator for fractional leverage.
} 
standard t-statistics, but have to be tackled in the context of the integration-cointegration properties through the Granger representation theorem. ${ }^{41}$

Following a non-parametric approach, Iliev and Welch (2010) model leverage ratios under the null hypothesis of no readjustment and find SOA estimates around zero. This fact suggests that the unit-root model is reasonable for the leverage of the average US firm. Although frictions can play a substantial role in shaping the cost-benefits adjustment (see e.g. Myers (1984) and Fischer et al. (1989)), Welch (2004, p. 123) argues that TO models with transaction costs cannot be entirely responsible for such low SOA estimates.

\section{A1.5 - Heterogeneous ways to escape from linearity}

Several papers try to emend some shortcomings listed above by relaxing the restrictive assumption of linearity. For example, regarding macroeconomic conditions, the SOA is significantly faster in good states (see e.g. Drobetz and Wanzenried (2006), Cook and Tang (2010), and Halling et al. (2012)). Regarding firm specific variables, Faulkender et al. (2012) find that large (in absolute value) operating cash flow drives more aggressive changes of leverage towards the target; in Byoun (2008) most adjustments of actual toward the target debt ratio occur when firms face a financial deficit or surplus; also in Dang et al. (2012) firms with large financing imbalances, large investments or low earnings volatility, adjust faster. In Warr et al. (2012) over-levered firms adjust rapidly when equity is overvalued, while undervalued firms adjust at a much slower pace. Baum et al. (2014) provide evidence that risk exerts asymmetric effects on SOAs, even after controlling for financial unbalances in driving actual/target leverage deviations. ${ }^{42}$ There are cases in which conclusions disagree: for example, Aybar-Arias et al. (2012) find that firms adjust faster when the actual debt is closer to the target because of lower adjustment costs, while in Drobetz and Wanzenried (2006) firms further away from optimal capital structure adjust more readily.

Faulkender et al. (2012) and Korteweg and Strebulaev (2012) use approaches technically more demanding (such as simulated moment estimation and (S, s) models) and carry evidence in favor of firms adjusting towards their target debt ratio with discontinuity, experiencing periods of inaction (i.e. not refinancing) when the actual debt lays inside upper/lower financing thresholds, while issuing transitory debt when actual debt is below the lower threshold.

\footnotetext{
${ }^{41}$ See Engle and Granger (1987). Ioannidis et al. (2003) explicitly stress the risk of spurious regressions using very persistent financial ratios.

${ }^{42}$ In this strand of research, both financial deficit/surplus and equity mispricing do not exert PO/MT effects as explicit explanatory $X_{i t}^{P O / M T}$ variables of model (3), but rather they drive the non-linear effects.
} 


\section{Appendix A2 - Relating the use of time dummies with the practice of data demeaning}

The estimation of a model with time dummies is equivalent to the estimation of the model (without $\tau_{t}$ ) where all the variables are demeaned. In this context, "demeaning" means that we measure the dependent variable of the leverage model with $L_{i t}^{d}=L_{i t}-\bar{L}_{t}$ rather than $L_{i t}$, where $\bar{L}_{t}=\frac{1}{N} \sum_{i=1}^{N} L_{i t}(N$ is the number of firms in the panel).

The inclusion of time effects $\tau_{t}$ (or demeaning model's variables) under the assumption of stationary variables assumes that the disturbance for each firm in the panel can be decomposed into common disturbances that are shared by all the members of the panel, and independent idiosyncratic disturbances that are specific to each member.

To give the intuition with a simple example, let's start from the univariate model which in the main text has been introduced to assess for heterogeneity in the linear context:

$$
\Delta L_{i t}=\alpha_{i} L_{i t-1}+\mu_{i}+e_{i t}
$$

and demean its data:

$$
\Delta L_{i t}^{d}=\alpha_{i} L_{i t-1}^{d}+\mu_{i}+e_{i t}
$$

If we substitute the definition, given above, of demeaned data we have:

$$
\Delta L_{i t}=\alpha_{i}\left(L_{i t-1}-\bar{L}_{t-1}\right)+\mu_{i}+\Delta \bar{L}_{t}+e_{i t}
$$

where $\Delta \bar{L}_{t}$ proxies the shocks common to all $N$ members of the panel and $e_{i t}$ embodies all other idiosyncratic shocks. As shown in equation (A2.3), estimating model (A2.1) with demeaned data assumes an equilibrium-correction mechanism (EqCM) process of adjustment where individual debt ratios converge to the heterogeneous target $L_{i t}^{*}=\frac{\mu_{i}}{-\alpha_{i}}+\bar{L}_{t}$.

Model (A2.3) can be augmented, as the Dickey-Fuller test equation can be, to fix residuals' autocorrelation problem. In this case, the dynamic specification (A2.3) is still an EqCM:

$$
\Delta L_{i t}=\alpha_{i}\left(L_{i t-1}-L_{i t-1}^{*}\right)+\sum_{j=1}^{p_{i}} \lambda_{i j} \Delta L_{i t-j}+\sum_{j=0}^{p_{i}} \lambda_{i j} \Delta \bar{L}_{t-j}+\omega_{i t}
$$

which corresponds to the Dickey-Fuller equation augmented by the changes in the common driving component $\Delta \bar{L}_{t-j}$.

For a theoretical justification of a slight generalization of model (A2.4), see the cross sectional augmented Dickey-Fuller (CADF) test of Pesaran (2007), where the common stochastic disturbance is proxied by a single common factor independent from the idiosyncratic disturbances. 


\section{Appendix A3 - Data}

We start from a broad data-sample of firms drawn from the Compustat database and covering the period 1950-2012. The Compustat data-set contains information about balance sheet and income statement of more than 400,000 firms from different economic sectors such as agriculture, manufacturing or financial services, and more than 350 variables.

We first select firms that have an annual balance sheet with the closing date on the $31^{\text {st }}$ of December (291,880 observations which duration period equal to twelve months). We drop firms classified as Financial Services according to the variable Industry Format ${ }^{43}$ going to an unbalanced panel of 263,454 firm-year observations. We excluded firms-year observations with missing data on employees and total assets, with total debt negative or higher than total assets, with gross tangible and intangible capital stocks higher than total assets, with market value of leverage and effective interest rate outside the $1^{\text {st }}$ and $99^{\text {th }}$ percentiles. As standard in the literature, we also excluded all financial firms (SIC codes 6000-6999), and regulated firms (SIC codes 4900-4999), as well as companies involved in major mergers (Compustat footnote code $\mathrm{AB}$ ) are excluded. We end up with an unbalanced panel of 168,696 observations for 15,577 companies (going from about 350 companies in 1950 to more than 4,000 companies in 2011).

Total leverage is measured by debt ratio at book values, as the sum of short-term debt (Compustat current liabilities, item \#34) and long-term debt (item \#9) over total assets (item \#6); long and short term leverages are defined accordingly.

Table A3.1 presents the sample distribution by industry and the corresponding averages for total, long- and short-term debt ratios. The latter summarize the sectorial data which are used as targets in models where (possibly non stationary) TO determinants are measured as debt averages over time.

\section{Table A3.1 here}

In the cointegration experiments we add some explanatory variables which are standard in the empirical financial literature (see e.g. Frank and Goyal (2003), Flannery and Rangan (2006), and de Jong et al. (2011)). Variable (1) of Section 4.2 represents guarantees, which are measured as fixed asset proportion, i.e. property, plant, and equipment over total assets (Compustat item \#14 / item \#6). Cashflow (variable (2)) is computed as income before extraordinary items (item \#123) plus extraordinary items and discontinued operations (item \#124) plus depreciation and amortization (item \#125) plus equity in net loss - earnings (item \#106) plus sale of property plant

\footnotetext{
${ }^{43}$ According to the Standard \& Poor Compustat Xpressfeed manual "Understanding the data", Industry Format represents company industry format at record level by identifying the basic financial presentation - mainly Financial Services (FS) versus Industrial format (INDL).
} 
and equipment and investments - gain (loss) (item \#213) plus funds from operations - other item \#217) plus exchange rate effect (item \#314) (plus deferred taxes (item \#126) and sources of funds other (item \#218) if format code for the cash flow statement is equal to 1, 2 and 3). ${ }^{44}$ The relative cost of capital (variable (3)) is given by (libor/100) - (ratedebt $\times(1$-TaxRate)), where ratedebt is interest and related expense - total (item \#15) divided by lagged total debt and TaxRate is the corporate statutory tax rate. Non-debt tax shields (variable (4)) are given by depreciation as a proportion of total assets (Compustat item \#14 / item \#6).

\footnotetext{
${ }^{44}$ The data from 1971 to 1987 is from the "Cash Statement by Sources and Use of funds" (Compustat format codes 1, 2, 3 ); the structure has funds from operations plus other sources of funds minus uses of working capital equals change in working capital. Beginning in 1988, most firms start reporting "Statement of Cash Flows" (format code 7), structured as income plus indirect operating activities plus investing activities plus financing activities equals change in cash and cash equivalents (Frank and Goyal (2003)).
} 


\section{References}

Alti, A. (2006), "How persistent is the impact of market timing on capital structure?", Journal of Finance, Vol. 61, No. 4, pp. 1681-1710.

Antoniou, A., Guney Y. and Paudyal C. (2008), "The determinants of capital structure: capital market oriented versus bank oriented institutions", Journal of Financial and Quantitative Analysis, Vol. 43, pp. 59-92.

Auerbach, A. J. (1985), "Real determinants of corporate leverage", in B. M. Friedman (ed.), Corporate Capital Structures in the United States, NBER, University of Chicago Press, pp. 301-322.

Aybar-Arias C., A. Casino-Martinez and J. Lopez-Gracia (2012), "On the adjustment speed of SMEs to their optimal capital structure", Small Business Economics, Vol. 39, pp. 977-996.

Baker, M. and J. Wurgler (2002), "Market timing and capital structure", Journal of Finance, Vol. 57, No. 1, pp. 1-32.

Banerjee, A., J. J. Dolado and R. Mestre (1998), "Error-correction mechanism tests for cointegration in a single-equation framework", Journal of Time Series Analysis, Vol. 19, No. 3, pp. 267-283.

Baum, C. F., M. Caglayan and A. Rashid (2014), "Capital structure adjustments: do macroeconomic and business risks matter?", Boston College Working Papers in Economics, No. 834.

Berben, R. P. and D. van Dijk (1999), "Unit root tests and asymmetric adjustment: a reassessment", Econometric Institute Report, No. EI-9902/A.

Bevan A. A. and J. Danbolt (2002), "Capital structure and its determinants in the UK - a decompositional analysis", Applied Financial Economics, Vol. 12, pp. 159-170.

Bontempi, M. E. (2002), "The dynamic specification of the modified pecking order theory: its relevance to Italy", Empirical Economics, Vol. 27, No. 1, pp. 1-22.

Bontempi, M. E. and R. Golinelli (2012); " The effect of neglecting the slope parameters' heterogeneity on dynamic models of corporate capital structure", Quantitative Finance, Vol. 12, No. 11, pp. 1733-1751.

Boswijk, H. P. (1994), "Testing for an unstable root in conditional and unconditional error correction models", Journal of Econometrics, Vol. 63, pp. 37-60.

Bradley, M., G. A. Jarrell and E. H. Kim (1984), "On the existence of an optimal capital structure: theory and evidence", Journal of Finance, Vol. 39, No. 3, pp. 857-880.

Brounen, D., A. de Jong and K. Koedijk (2006), "Capital structure policies in Europe: survey evidence", Journal of Banking and Finance, Vol. 30, pp. 1409-1442.

Brunello, G., C. Lupi and P. Ordine (2000), "Regional disparities and the Italian NAIRU", Oxford Economic Papers, Vol. 52, pp. 146-177.

Byoun, S. (2008), "How and when do firms adjust their capital structures toward targets?", Journal of Finance, Vol. 63, No. 6, pp. 3069-3096.

Campbell, J. Y. and P. Perron (1991), "Pitfalls and opportunities: what macroeconomists should know about unit roots", in O. J. Blanchard and S. Fischer (eds.), NBER Macroeconomics Annual 1991, MIT Press. 
Canarella, G., S. M. Miller and M. M. Nouray (2013), "Firm profitability: mean-reverting or random-walk behavior?", Journal of Economics and Business, Vol. 66, pp. 76-97.

Chang, X. and S. Dasgupta (2009), "Target behavior and financing: how conclusive is the evidence", Journal of Finance, Vol. 64, No. 4, pp. 1767-1796.

Chen, L. and X. Zhao (2007), "Mechanical mean reversion of leverage ratios", Economics Letters, Vol. 95, pp. 223-229.

Chortareas, G. and G. Kapetanios (2009), "Getting PPP right: indentifying mean-reverting real exchange rates in panels", Journal of Banking and Finance, Vol. 33, pp. 390-404.

Clemente, J., A.Montanes and M Reyes (1998), "Testing for unit roots in variables with double change in mean", Economics Letters, Vol.59, pp. 175-182.

Cook, D. O. and T. Tang (2010), "Macroeconomic conditions and capital structure adjustment speed", Journal of Corporate Finance, Vol. 16, pp. 73-87.

Costantini, M. and C. Lupi (2014), "Identifying I(0) series in macro-panels: are sequantial panel selection methods useful?", Economics \& Statistics Discussion Paper, No. 073/14. http://ideas.repec.org/p/mol/ecsdps/esdp14073.html

Dang, V. A., M. Kim and Y. Shin (2012), "Asymmetric capital structure adjustments: new evidence from dynamic panel threshold models", Journal of Empirical Finance, Vol. 19, pp. 465-482.

DeAngelo, H., L. DeAngelo and T. M. Whited (2011), "Capital structure dynamics and transitory debt", Journal of Financial Economics, Vol. 99, pp. 235-261.

DeAngelo, H. and R. Roll (2013), "How stable are corporate capital structures?", Journal of Finance, forthcoming.

de Haas, R. and M. Peeters (2006), "The dynamic adjustment towards target capital structures of firms in transition economies", Economics of Transition, Vol. 14, No. 1, pp. 133-169.

de Jong, A., M. Verbeek and P. Verwijmeren (2011), "Firms' debt-equity decisions when the static tradeoff theory and the pecking order theory disagree", Journal of Banking and Finance, Vol. 35, pp. 1303-1314.

de Miguel, A. and J. Pindado (2001), "Determinants of capital structure: new evidence from Spanish panel data", Journal of Corporate Finance, Vol. 7, pp. 77-99.

Dickey, D. A. and W. A. Fuller (1979), "Distribution of the estimators for autoregressive time series with a unit root", Journal of American Statistical Association, Vol. 74, pp. 427-431.

D'Mello, R. and J Farhat (2008), "A comparative analysis of proxies for an optimal leverage ratio", Review of Financial Economics, Vol. 17, pp. 213-227.

Drobetz, W. and G. Wanzenried (2006), "What determines the speed of adjustment to the target capital structure?", Applied Financial Economics, Vol. 16, No. 13, pp. 941-958.

Eckbo, B. E. and M. Kisser (2014), "Corporate debt issues and leverage dynamics", SSRN Electronic Paper Collection, No. 2234435.

Elliott, G. T., J. Rothemberg, and J. H. Stock (1996), "Efficient tests for an autoregressive unit root", Econometrica, Vol. 64, No. 4, pp. 813-836.

Elsas, R. and D. Florysiak (2011), "Heterogeneity in the speed of adjustment toward target leverage", International Review of Finance, Vol. 11. No. 2, pp. 181-211.

Elsas, R. and D. Florysiak (2014), "Dynamic capital structure adjustment and the impact of fractional dependent variables", Journal of Financial and Quantitative Analysis, forthcoming. 
Enders, W. and C. W. J. Granger (1998), "Unit-root tests and asymmetric adjustment with an example using the term structure of interest rates", Journal of Business and Economic Statistics, Vol. 16, No. 3, pp. 304-311.

Engle, R. F. and C. W. J. Granger (1987), "Co-integration and error correction: representation, estimation, and testing", Econometrica, Vol. 55, No. 2, pp. 251-276.

Fama, E. F. and K. R. French (2002), "Testing trade-off and pecking order predictions about dividends and debt", The Review of Financial Studies, Vol. 15, No. 1, pp. 1-33.

Fama, E. F. and K. R. French (2012), "Capital structure choices”, Critical Finance Review, Vol. 1, pp. 59-101.

Faulkender, M., M. J. Flannery, K. Watson Hankins and J. M. Smith (2012), "Cash flows and leverage adjustments", Journal of Financial Economics, Vol. 103, pp. 632-646.

Fischer, E. O., R. Heinkel and J. Zechner (1989), "Dynamic capital structure choice", Journal of Finance, Vol. 44, No. 1, pp. 19-40.

Flannery, M. J. and K. Watson Hankins (2013), "Estimating dynamic panel models in corporate finance", Journal of Corporate Finance, Vol. 19, pp. 1-19.

Flannery, M. J. and K. P. Rangan (2006), "Partial adjustment toward target capital structures", Journal of Financial Economics, Vol. 79, pp. 469-506.

Frank, M. Z. and V. K. Goyal (2003), "Testing the Pecking Order Theory of Capital Structure", Journal of Financial Economics, Vol. 67, pp. 217-248.

Frank, M. Z. and V. K. Goyal (2008), "Trade-off and pecking order theories of debt", in B. E. Eckbo (ed.), Handbook of Corporate Finance: Empirical Corporate Finance, Vol. 2, Ch. 12, Elsevier/North-Holland.

Frank, M. Z. and V. K. Goyal (2009), "Capital structure decisions: which factors are reliably important?", Financial Management, Spring, pp. 1-37.

Frank, M. Z. and T, Shen (2014), "Common factors in corporate capital structure", mimeo.

Gaud, P., M. Hoesli and A. Bender (2007), "Debt-equity choice in Europe", International Review of Financial Analysis, Vol. 16, pp. 201-222.

Gilson, S. C. (1997), "Transaction costs and capital structure choice: evidence from financially distressed firms", Journal of Finance, Vol. 52, No. 1, pp. 161-196.

Gonzalo, J. and T.-H. Lee (1998), "Pitfalls in testing for long run relationships", Journal of Econometrics, Vol. 86, 129-154.

Gordon, R. H. (1985), "Comment", in B. M. Friedman (ed.), Corporate Capital Structures in the United States, NBER, University of Chicago Press, pp. 322-324.

Graham, J. R. and C. Harvey (2001), "The theory and practice of corporate finance: evidence from the field", Journal of Financial Economics, Vol. 60, No. 2-3, pp. 187-243.

Graham, J. R. and M. T. Leary (2011), "A review of empirical capital structure research and directions for the future", Annual Review of Financial Economics, Vol. 3, pp. 309-345

Granger, C. W. J. and P. Newbold (1974), "Spurious regressions in econometrics", Journal of Econometrics, Vol. 2, pp. 111-120.

Gregory A. W., A. A. Haugh and N. Lomuto (2004), "Mixed signals amongs tests for cointegration", Journal of Applied Econometrics, Vol. 19, pp. 89-98. 
Guney, Y., L. Li and R. Fairchild (2011), "The relationship between product market competition and capital structure in Chinese firms", International Review of Financial Analysis, Vol. 20, pp. 51-51.

Hadri, K. (2000), "Testing for stationarity in heterogeneous panel data", Econometrics Journal, Vol. 3, pp. 148-161.

Hall, A. D., H. M. Anderson, C. W. J. Granger (1992), "A cointegration analysis of treasury bill yields", The Review of Economics and Statistics, Vol. 74, pp. 116-126.

Halling, M., J. Yu and J. Zechner (2012), "Leverage dynamics over the business cycle", AFA 2012 Chicago Meetings Paper.

Harris, M. and A. Raviv (1991), "The theory of capital structure”, Journal of Finance, Vol. 46, pp. 297-355.

Hovakimian, A. (2006), “Are observed capital structure determined by equity market timing?", Journal of Financial and Quantitative Analysis, Vol. 41, No. 1, pp. 221-243.

Hovakimian, A. and G. Li (2011), "In search of conclusive evidence: how to test for adjustment to target capital structure", Journal of Corporate Finance, Vol. 17, pp. 33-44.

Hovakimian, A., T. Opler and S. Titman (2001), "The debt-equity choice", Journal of Financial and Quantitative Analysis, Vol. 36, No. 1, pp. 1-24.

Huang, R. and J. R. Ritter (2009), "Testing theories of capital structure and estimating the speed of adjustment", Journal of Financial and Quantitative Analysis, Vol. 44, No. 2, pp. 237-271.

Iliev, P. and I. Welch (2010), "Reconciling estimates of the speed of adjustment of leverage ratios", SSRN: http://ssrn.com/abstract $=1542691$

Im, K. S., H. M. Pesaran and Y. Shin (2003), "Testing for unit roots in heterogeneous panels", Journal of Econometrics, Vol. 115, pp. 53-74.

Imbs, J., H. Mumtaz, M. O. Ravn and H. Rey (2005), "PPP Strikes Back: Aggregation and the Real Exchange Rate", The Quarterly Journal of Economics, Vol. 120, No. 1, pp. 1-43.

Ioannidis, C., D. A. Peel and M. J. Peel (2003), The time series properties of financial ratios: Lev revisited", Journal of Business Finance \& Accounting, Vol. 30, N0. 5-6, pp. 699-714.

Johansen, S. (1995), Likelihood-based Inference in Cointegrated Vector Autoregressive Models, Oxford University Press.

Kapetanios, G., Y. Shin and A. Snell (2003), "Testing for a unit root in the nonlinear STAR framework", Journal of Econometrics, Vol. 112, pp. 359-379.

Kayhan, A. and S. Titman (2007), "Firms' histories and their capital structures", Journal of Financial Economics, Vol. 83, pp. 1-32.

Kayo, E. K. and H. Kimura (2011), "Hierarchical determinants od capital structure", Journal of Banking and Finance, Vol. 35, pp. 358-371.

Korteweg, A. and M. Lemmon (2013), "Structural models of capital structure: a framework for model evaluation and testing", AFA 2013 San Diego Meetings Paper.

Korteweg, A. and I. A. Strebulaev (2012), "An (S,s) model of capital structure: theory and evidence", AFA 2012 Chicago Meetings Paper.

Leary, M. T. and M. R. Roberts (2005), “Do firms rebalance their capital structure?”, Journal of Finance, Vol. 60, No. 6, pp. 2575-2619. 
Lemmon, M. L., M. R. Roberts and J. F. Zender (2008), "Back to the beginning: persistence and the cross-section of corporate capital structure", Journal of Finance, Vol. 63, No. 4, pp. 15751608.

Lev, B. (1969), "Averages as targets for financial ratios", Journal of Accounting Research, Vol. 7, No. 2, pp. 290-299.

MacKay, P. and G. M.Phillips (2005), "How does industry affects firm financial structure?", The Review of Financial Studies, Vol. 18, No. 4, pp. 1433-1466.

McLeay, S. and M. Stevenson (2009), "Modelling the longitudinal properties of financial ratios", Applied Financial Economics, Vol. 19, pp. 305-318.

Myers, S. C. (1984), "The capital structure puzzle", Journal of Finance, Vol. 39, pp. 575-592.

Myers, S. C. and N. S. Majluf (1984), "Corporate financing and investment decisions when firms have information that investors do not have", Journal of Financial Economics, Vol. 13, pp. 187-221.

Nelson, C. R. and C. I. Plosser (1982), "Trends and random walks in macroeconomic time series", Journal of Monetary Economics, Vol.10, pp. 139-162.

$\mathrm{Ng}, \mathrm{S}$. and P. Perron (1995), "Unit root test in ARIMA models with data dependent methods for the selection of the truncation lag", Journal of the American Statistical Association, Vol. 90, pp. 268-281.

$\mathrm{Ng}$, S. and P. Perron (2001), "Lag length selection and the construction of unit root tests with good size and power", Econometrica, Vol. 69, No. 6, pp. 1519-1554.

Noulas, A. and G. Genimakis (2011), "The determinants of capital structure choice: evidence from Greek listed companies", Applied Financial Economics, Vol. 21, No. 6, pp. 379-387.

Nunkoo, P. K. and A. Boateng (2010), "The empirical determinants of target capital structure and adjustment to long-run target: evidence from Canadian firms", Applied Economic Letters, Vol. 17, pp. 983-990.

Ozkan, A. (2001), "Determinants of capital structure and adjustment to long run target: evidence from UK company panel data", Journal of Business Finance and Accounting, Vol. 28, No. 2, pp. 175-198.

Oztekin, O and M. J. Flannery (2012), "Institutional determinants of capital structure adjustment speeds", Journal of Financial Economics, Vol. 103, pp. 88-112.

Parsons, C. and S. Titman (2008), "Empirical capital structure: a review", Foundations and Trends in Finance, Vol. 3, No. 1, pp. 1-93.

Pedroni, P. (1999), "Critical values for cointegration tests in heterogeneous panels with multiple regressors", Oxford Bulletin of Economics and Statistics, Vol.61, special issue, pp. 653-670.

Peel, D. A., M. J. Peel and I. A. Venetis (2004), "Further empirical analysis of the time series properties of financial ratios based on a panel data approach", Applied Financial Economics, Vol. 14, pp. 155-163.

Pereira-Alves, P. and M. A. Ferreira (2011), "Capital structure and law around the world", Journal of Multinational Financial Management, Vol. 21, pp. 119-150.

Perron, P. (1989), "The great crash, the oil price shock and the unit root hypothesis", Econometrica, Vol. 57, No. 6, pp. 1361-1401.

Perron, P. and Vogelsang (1992), "Nonstationarity and level shifts with an application to purchasing power parity", Journal of Business and Economic Statistics, Vol.10, pp. 301-320. 
Pesaran, H. M. (2007), "A simple panel unit root test in the presence of cross section dependence", Journal of Applied Econometrics, Vol. 22, No. 2, pp. 265-312.

Pesaran, M. H. (2012), “On the interpretation of panel unit root tests", Economics Letters, Vol. 116, pp. 545-546.

Pesaran, H. M., Y. Shin and R. P. Smith (1999), "Pooled mean group rstimation of dynamic heterogeneous panels", Journal of American Statistical Association, Vol. 94, No. 446, pp. 621-634.

Pesaran, H. M. and R. P. Smith (1995), "Estimating long-run relationships from dynamic heterogeneous panels", Journal of Econometrics, Vol. 68, pp. 79-113.

Phillips, P. C. B. and H. R. Moon (2000), "Nonstationary panel data analysis: an overview of some recent developments", Econometric Reviews, Vol. 19, pp. 263-286.

Raymar, S. (1991), “A model of capital structure when earnings are mean-reverting”, Journal of Financial and Quantitative Analysis, Vol. 26, No. 3, pp. 327-344.

Roberts, M. R. (2002), "The dynamics of capital structure: an empirical analysis of a partially observable system", Fuqua School of Business Working Paper, Duke University.

Sarkar, S. and F. Zapatero (2003), "The trade-off model with mean reverting earnings: theory and empirical tests", Economic Journal, Vol. 113, October, 834-860.

Shyam-Sunder, L. and S.C. Myers (1999), "Testing static trade off against pecking order models of capital structure", Journal of Financial Economics, Vol. 51, pp. 219-244; see also NBER Working Paper, No. 4722, April 1994.

Stock, J. H. (1987), "Asymptotic properties of least squares estimators of co-integrating vectors", Econometrica, Vol. 55, No. 5, pp. 1035-1056.

Taggart, R. A. (1977), "A model of corporate financing decisions", Journal of Finance, Vol. 32, No. 5, pp. 1467-84.

Titman, S. and S. Tsyplakov (2007), "A dynamic model of optimal capital structure", Review of Finance, Vol. 11, pp. 201-451.

Warr, R. S., W. B. Elliott, J. Koeter-Kant and O. Oztekin (2012), "Equity mispricing and leverage adjustment costs", Journal of Financial and Quantitative Analysis, Vol. 47, No. 3, pp. 589616.

Welch, I. (2004), "Capital structure and stock returns", Journal of Political Economy, Vol. 112, No. 1, pp. 106-131

Westerlund, J. (2007), "Testing for error correction in panel data", Oxford Bulletin of Economics and Statistics, Vol.69, No. 6, pp. 709-748.

Yang, G. J.-A., H. Chueh and C.-H. Lee (2014), "Examining the theory of capital structure: signal factor hypothesis", Applied Economics, Vol. 46, No. 10, 1127-1133. 
Tables and Figures

Tab. 1 - Schematic view of the ADF tests and its weaknesses

When the theory actually valid is:

$\mathrm{PO} / \mathrm{MT}$

TO with stationary drivers

\begin{tabular}{|c|c|c|}
\hline $\begin{array}{l}\text { ADF null } \\
\text { that } \alpha_{i}=0\end{array}$ & $\begin{array}{l}\text { ADF is right, as in this column firms } \\
\text { are assumed to follow PO/MT theories } \\
\text { and do not have a target leverage (SOA } \\
\text { is zero). Note that ADF may lack } \\
\text { power (in the cell on the right), and/or } \\
\text { size (in the cell below). } \\
\text { ADF is wrong, as it suggests that firms' } \\
\text { leverage reverts towards a fixed target } \\
\text { over time. Among the causes of ADF } \\
\text { over-rejection note: sizeable MA } \\
\text { terms, variability of AR parameters, } \\
\text { breaks at the beginning of the time } \\
\text { series. }\end{array}$ & $\begin{array}{l}\text { ADF is wrong, as it does not reject PO/MT } \\
\text { which is false. This failure can be do either } \\
\text { to not constant SOA (non-linearity may be a } \\
\text { cause of equation (10) mis-specification, see } \\
\text { case A2), or to breaks/shifts in leverage } \\
\text { levels (see case B1). An additional issue is } \\
\text { the non-stationarity of the target leverage } \\
\text { determinants (see cases B2, C1). } \\
\text { ADF is right, as in this column firms are } \\
\text { assumed to follow TO with stationary } \\
\text { drivers, which imply that the target leverage } \\
\text { is constant over time. }\end{array}$ \\
\hline
\end{tabular}


Tab. 2 - Shares of firms with target reverting debt ratios by term structure and in alternative balanced panels (deterministic targets)

\begin{tabular}{|c|c|c|c|c|c|c|c|c|c|c|c|c|c|c|c|}
\hline \multirow{2}{*}{\multicolumn{2}{|c|}{ Begin End }} & \multirow[b]{2}{*}{$\begin{array}{l}\text { Time } \\
\text { span }\end{array}$} & \multirow[b]{2}{*}{$\begin{array}{l}\text { \# of } \\
\text { firms }\end{array}$} & \multicolumn{2}{|c|}{$\begin{array}{l}\text { Linear around } \\
\text { a fixed target } b\end{array}$} & \multicolumn{5}{|c|}{$\begin{array}{l}\text { Asymmetric or non-linear around } \\
\text { a fixed target }\end{array}$} & \multicolumn{3}{|c|}{$\begin{array}{l}\text { Linear around } \\
\text { a broken target }\end{array}$} & \multicolumn{2}{|c|}{$\begin{array}{l}\text { Linear with industry } \\
\text { time varying targets }\end{array}$} \\
\hline & & & & $\mathrm{ADF}$ & DFGLS & BvD & $+>-$ & $+=-$ & $+<-$ & KSS & BT & $\begin{array}{r}\text { One } \\
\text { break }\end{array}$ & $\begin{array}{r}\text { Two } \\
\text { breaks } \\
\end{array}$ & mean & median \\
\hline \multicolumn{16}{|c|}{ Short term debt ratios ${ }^{a}$} \\
\hline 1950 & 2011 & 62 & 50 & 0.440 & 0.520 & 0.680 & 0.706 & 0.265 & 0.029 & 0.480 & 0.740 & 0.649 & 0.351 & 0.520 & 0.440 \\
\hline 1960 & 2011 & 52 & 97 & 0.583 & 0.567 & 0.711 & 0.623 & 0.333 & 0.043 & 0.474 & 0.773 & 0.680 & 0.320 & 0.557 & 0.573 \\
\hline 1970 & 2011 & 42 & 161 & 0.640 & 0.491 & 0.733 & 0.534 & 0.407 & 0.059 & 0.488 & 0.776 & 0.760 & 0.240 & 0.590 & 0.566 \\
\hline 1975 & 2011 & 37 & 196 & 0.631 & 0.520 & 0.714 & 0.493 & 0.471 & 0.036 & 0.523 & 0.740 & 0.752 & 0.248 & 0.590 & 0.577 \\
\hline 1980 & 2011 & 32 & 227 & 0.602 & 0.520 & 0.670 & 0.526 & 0.461 & 0.013 & 0.522 & 0.731 & 0.735 & 0.265 & 0.558 & 0.569 \\
\hline 1985 & 2011 & 27 & 290 & 0.561 & 0.507 & 0.641 & 0.446 & 0.527 & 0.027 & 0.458 & 0.662 & 0.729 & 0.271 & 0.552 & 0.531 \\
\hline 1990 & 2011 & 22 & 412 & 0.542 & 0.430 & 0.604 & 0.402 & 0.594 & 0.004 & -- & 0.585 & 0.714 & 0.286 & 0.549 & 0.550 \\
\hline \multicolumn{16}{|c|}{ Long term debt ratios ${ }^{a}$} \\
\hline 1950 & 2011 & 62 & 50 & 0.163 & 0.160 & 0.280 & 0.286 & 0.214 & 0.500 & 0.224 & 0.320 & 0.500 & 0.500 & 0.143 & 0.163 \\
\hline 1960 & 2011 & 52 & 97 & 0.253 & 0.206 & 0.402 & 0.308 & 0.359 & 0.333 & 0.253 & 0.371 & 0.528 & 0.472 & 0.211 & 0.170 \\
\hline 1970 & 2011 & 42 & 161 & 0.233 & 0.335 & 0.348 & 0.304 & 0.286 & 0.411 & 0.297 & 0.329 & 0.642 & 0.358 & 0.222 & 0.237 \\
\hline 1975 & 2011 & 37 & 196 & 0.240 & 0.306 & 0.332 & 0.200 & 0.415 & 0.385 & 0.215 & 0.342 & 0.627 & 0.373 & 0.196 & 0.183 \\
\hline 1980 & 2011 & 32 & 227 & 0.242 & 0.326 & 0.317 & 0.236 & 0.417 & 0.347 & 0.194 & 0.344 & 0.551 & 0.449 & 0.246 & 0.204 \\
\hline 1985 & 2011 & 27 & 290 & 0.256 & 0.283 & 0.303 & 0.182 & 0.455 & 0.364 & 0.187 & 0.421 & 0.574 & 0.426 & 0.237 & 0.241 \\
\hline 1990 & 2011 & 22 & 412 & 0.216 & 0.250 & 0.294 & 0.223 & 0.479 & 0.298 & -- & 0.420 & 0.497 & 0.503 & 0.219 & 0.220 \\
\hline \multicolumn{16}{|c|}{ Total debt ratios ${ }^{a}$} \\
\hline 1950 & 2011 & 62 & 50 & 0.220 & 0.160 & 0.360 & 0.500 & 0.222 & 0.278 & 0.180 & 0.300 & 0.667 & 0.333 & 0.260 & 0.300 \\
\hline 1960 & 2011 & 52 & 97 & 0.229 & 0.258 & 0.392 & 0.342 & 0.421 & 0.237 & 0.175 & 0.309 & 0.667 & 0.333 & 0.198 & 0.188 \\
\hline 1970 & 2011 & 42 & 161 & 0.306 & 0.292 & 0.391 & 0.206 & 0.476 & 0.317 & 0.231 & 0.348 & 0.554 & 0.446 & 0.239 & 0.196 \\
\hline 1975 & 2011 & 37 & 196 & 0.246 & 0.276 & 0.316 & 0.258 & 0.452 & 0.290 & 0.193 & 0.337 & 0.561 & 0.439 & 0.202 & 0.201 \\
\hline 1980 & 2011 & 32 & 227 & 0.267 & 0.308 & 0.335 & 0.276 & 0.487 & 0.237 & 0.194 & 0.339 & 0.545 & 0.455 & 0.232 & 0.204 \\
\hline 1985 & 2011 & 27 & 290 & 0.254 & 0.283 & 0.331 & 0.219 & 0.385 & 0.396 & 0.184 & 0.376 & 0.532 & 0.468 & 0.230 & 0.191 \\
\hline 1990 & 2011 & 22 & 412 & 0.208 & 0.252 & 0.286 & 0.254 & 0.466 & 0.280 & -- & 0.383 & 0.437 & 0.563 & 0.210 & 0.224 \\
\hline
\end{tabular}

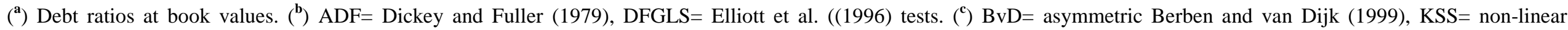

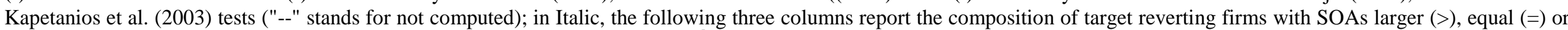

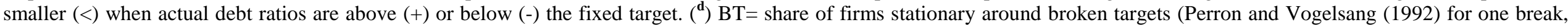

Clemente et al. (1998) for two breaks); in Italic, the following two columns report the composition of the stationary firms on the basis of the number of breaks in the target. 
Tab. 3 - Average SOA estimates by groups of non-reverting and reverting firms on the basis of alternative univariate models. ${ }^{a}$

\begin{tabular}{|c|c|c|c|c|c|c|c|c|c|c|c|c|c|c|}
\hline \multirow{2}{*}{\multicolumn{2}{|c|}{ Begin End }} & \multirow[t]{2}{*}{$\begin{array}{l}\text { Time } \\
\text { span }\end{array}$} & \multirow[t]{2}{*}{$\begin{array}{l}\text { \# of } \\
\text { firms }\end{array}$} & \multirow[t]{2}{*}{$\begin{array}{l}\text { MG of non- } \\
\text { reverting firms }\end{array}$} & \multirow{2}{*}{ Linear } & \multicolumn{5}{|c|}{$\begin{array}{c}\text { MG of } \\
\text { reverting firms } \\
\text { Asymmetric adjustment dynamics }\end{array}$} & \multicolumn{2}{|c|}{ Breaking target } & \multicolumn{2}{|c|}{ Time varying target } \\
\hline & & & & & & $\hat{\alpha}_{i}^{+}$ & $\hat{\alpha}_{i}^{-}$ & $\hat{\alpha}_{i}^{+}=\hat{\alpha}_{i}^{-}$ & $\hat{\alpha}_{i}^{+}$ & $>\hat{\alpha}_{i}^{-}$ & One & Two & mean & median \\
\hline \multicolumn{15}{|c|}{ Short term debt ratios $b$} \\
\hline 1950 & 2011 & 62 & 50 & -0.194 & -0.516 & -0.968 & -0.138 & -0.463 & -0.510 & -1.746 & -0.727 & -0.820 & -0.479 & -0.533 \\
\hline 1960 & 2011 & 52 & 97 & -0.229 & -0.544 & -1.067 & -0.155 & -0.525 & -0.436 & -1.508 & -0.816 & -0.845 & -0.538 & -0.554 \\
\hline 1970 & 2011 & 42 & 161 & -0.261 & -0.638 & -1.214 & -0.176 & -0.607 & -0.605 & -1.755 & -0.851 & -0.933 & -0.614 & -0.637 \\
\hline 1975 & 2011 & 37 & 196 & -0.272 & -0.711 & -1.317 & -0.193 & -0.706 & -0.879 & -1.914 & -0.933 & -0.945 & -0.672 & -0.699 \\
\hline 1980 & 2011 & 32 & 227 & -0.314 & -0.763 & -1.377 & -0.199 & -0.816 & -0.623 & -1.834 & -0.987 & -1.039 & -0.742 & -0.749 \\
\hline 1985 & 2011 & 27 & 290 & -0.339 & -0.827 & -1.404 & -0.208 & -0.848 & -0.458 & -1.526 & -0.995 & -1.174 & -0.799 & -0.824 \\
\hline 1990 & 2011 & 22 & 412 & -0.391 & -0.845 & -1.523 & -0.192 & -0.850 & -0.695 & -1.974 & -1.012 & -1.196 & -0.858 & -0.856 \\
\hline \multicolumn{15}{|c|}{ Long term debt ratios ${ }^{b}$} \\
\hline 1950 & 2011 & 62 & 50 & -0.129 & -0.323 & -0.877 & -0.098 & -0.324 & -0.084 & -1.109 & -0.590 & -0.656 & -0.303 & -0.295 \\
\hline 1960 & 2011 & 52 & 97 & -0.160 & -0.345 & -1.001 & -0.125 & -0.343 & -0.108 & -1.403 & -0.654 & -0.790 & -0.348 & -0.372 \\
\hline 1970 & 2011 & 42 & 161 & -0.193 & -0.499 & -1.130 & -0.148 & -0.481 & -0.142 & -1.503 & -0.757 & -0.800 & -0.456 & -0.436 \\
\hline 1975 & 2011 & 37 & 196 & -0.202 & -0.539 & -1.327 & -0.139 & -0.544 & -0.172 & -1.470 & -0.811 & -0.936 & -0.497 & -0.490 \\
\hline 1980 & 2011 & 32 & 227 & -0.222 & -0.603 & -1.307 & -0.136 & -0.626 & -0.183 & -1.593 & -0.822 & -0.942 & -0.558 & -0.551 \\
\hline 1985 & 2011 & 27 & 290 & -0.256 & -0.643 & -1.393 & -0.179 & -0.625 & -0.230 & -1.574 & -0.877 & -1.142 & -0.632 & -0.628 \\
\hline 1990 & 2011 & 22 & 412 & -0.299 & -0.701 & -1.489 & -0.183 & -0.624 & -0.268 & -1.719 & -1.008 & -1.068 & -0.716 & -0.712 \\
\hline \multicolumn{15}{|c|}{ Total debt ratios ${ }^{b}$} \\
\hline 1950 & 2011 & 62 & 50 & -0.121 & -0.318 & -0.840 & -0.081 & -0.311 & -0.082 & -1.157 & -0.521 & -0.754 & -0.301 & -0.289 \\
\hline 1960 & 2011 & 52 & 97 & -0.151 & -0.371 & -1.090 & -0.117 & -0.340 & -0.106 & -1.367 & -0.585 & -0.738 & -0.387 & -0.390 \\
\hline 1970 & 2011 & 42 & 161 & -0.180 & -0.441 & -1.115 & -0.123 & -0.426 & -0.143 & -1.458 & -0.753 & -0.893 & -0.466 & -0.459 \\
\hline 1975 & 2011 & 37 & 196 & -0.206 & -0.499 & -1.396 & -0.109 & -0.504 & -0.181 & -1.582 & -0.815 & -0.986 & -0.522 & -0.500 \\
\hline 1980 & 2011 & 32 & 227 & -0.219 & -0.532 & -1.420 & -0.150 & -0.538 & -0.190 & -1.647 & -0.864 & -0.974 & -0.553 & -0.556 \\
\hline 1985 & 2011 & 27 & 290 & -0.258 & -0.595 & -1.559 & -0.198 & -0.560 & -0.216 & -1.588 & -0.859 & -1.037 & -0.595 & -0.621 \\
\hline 1990 & 2011 & 22 & 412 & -0.292 & -0.696 & -1.568 & -0.220 & -0.641 & -0.234 & -1.700 & -1.085 & -1.079 & -0.711 & -0.686 \\
\hline
\end{tabular}

$\left({ }^{a}\right) \mathrm{MG}=$ mean group estimates, i.e. averages of individual SOA estimates within the groups whose shares are reported in Table 2. $\left({ }^{\mathbf{b}}\right)$ Debt ratios at book values. 
Tab. 4 - Shares of firms with stochastic targets, and SOA estimates by groups of reverting firms.

\begin{tabular}{|c|c|c|c|c|c|c|c|c|c|c|}
\hline \multirow[b]{2}{*}{ Begin } & \multirow[b]{2}{*}{ End } & \multirow[b]{2}{*}{$\begin{array}{l}\text { Time } \\
\text { span }\end{array}$} & \multirow[b]{2}{*}{$\begin{array}{l}\text { \# of } \\
\text { firms }\end{array}$} & \multirow[b]{2}{*}{ Incomplete } & \multicolumn{2}{|c|}{ Engle-Granger (EG) } & \multicolumn{3}{|c|}{$\begin{array}{l}\text { Reverting with alternative } \\
\text { approaches }\end{array}$} & \multirow[b]{2}{*}{ SOA (EG) } \\
\hline & & & & & $\begin{array}{l}\text { Non- } \\
\text { reverting } \\
\text { firms }\end{array}$ & $\begin{array}{l}\text { Reveting } \\
\text { firms }\end{array}$ & Johansen & $\begin{array}{l}\text { Banerjee } \\
\text { et al. }\end{array}$ & Boswijk & \\
\hline \multicolumn{11}{|c|}{ Short term debt ratios } \\
\hline 1950 & 2011 & 62 & 50 & 0.000 & 0.400 & 0.600 & 0.280 & 0.580 & 0.540 & -0.657 \\
\hline 1960 & 2011 & 52 & 97 & 0.010 & 0.396 & 0.594 & 0.313 & 0.542 & 0.531 & -0.705 \\
\hline 1970 & 2011 & 42 & 161 & 0.012 & 0.422 & 0.566 & 0.296 & 0.497 & 0.535 & -0.815 \\
\hline 1975 & 2011 & 37 & 196 & 0.015 & 0.410 & 0.575 & 0.332 & 0.492 & 0.482 & -0.903 \\
\hline 1980 & 2011 & 32 & 227 & 0.009 & 0.449 & 0.542 & 0.302 & 0.449 & 0.489 & -0.976 \\
\hline 1985 & 2011 & 27 & 290 & 0.028 & 0.497 & 0.475 & 0.309 & 0.426 & 0.511 & -1.048 \\
\hline 1990 & 2011 & 22 & 412 & 0.034 & 0.614 & 0.352 & 0.304 & 0.402 & 0.588 & -1.228 \\
\hline \multicolumn{11}{|c|}{ Long term debt ratios } \\
\hline 1950 & 2011 & 62 & 50 & 0.000 & 0.800 & 0.200 & 0.120 & 0.120 & 0.140 & -0.411 \\
\hline 1960 & 2011 & 52 & 97 & 0.021 & 0.832 & 0.147 & 0.095 & 0.158 & 0.211 & -0.517 \\
\hline 1970 & 2011 & 42 & 161 & 0.025 & 0.803 & 0.172 & 0.127 & 0.185 & 0.293 & -0.640 \\
\hline 1975 & 2011 & 37 & 196 & 0.026 & 0.833 & 0.141 & 0.120 & 0.120 & 0.272 & -0.779 \\
\hline 1980 & 2011 & 32 & 227 & 0.018 & 0.816 & 0.166 & 0.121 & 0.121 & 0.300 & -0.824 \\
\hline 1985 & 2011 & 27 & 290 & 0.024 & 0.792 & 0.184 & 0.163 & 0.159 & 0.357 & -0.859 \\
\hline 1990 & 2011 & 22 & 412 & 0.032 & 0.863 & 0.105 & 0.208 & 0.246 & 0.524 & -1.044 \\
\hline \multicolumn{11}{|c|}{ Total debt ratios } \\
\hline 1950 & 2011 & 62 & 50 & 0.000 & 0.860 & 0.140 & 0.200 & 0.040 & 0.220 & -0.401 \\
\hline 1960 & 2011 & 52 & 97 & 0.010 & 0.896 & 0.094 & 0.125 & 0.052 & 0.208 & -0.426 \\
\hline 1970 & 2011 & 42 & 161 & 0.019 & 0.823 & 0.158 & 0.133 & 0.082 & 0.304 & -0.546 \\
\hline 1975 & 2011 & 37 & 196 & 0.015 & 0.850 & 0.135 & 0.140 & 0.067 & 0.254 & -0.639 \\
\hline 1980 & 2011 & 32 & 227 & 0.009 & 0.880 & 0.111 & 0.151 & 0.076 & 0.284 & -0.765 \\
\hline 1985 & 2011 & 27 & 290 & 0.014 & 0.878 & 0.108 & 0.217 & 0.115 & 0.360 & -0.786 \\
\hline 1990 & 2011 & 22 & 412 & 0.024 & 0.906 & 0.070 & 0.189 & 0.197 & 0.550 & -1.057 \\
\hline
\end{tabular}


Fig. 1 - Total debt SOA for ESTAR adjusting firms over the sample 1980-2011

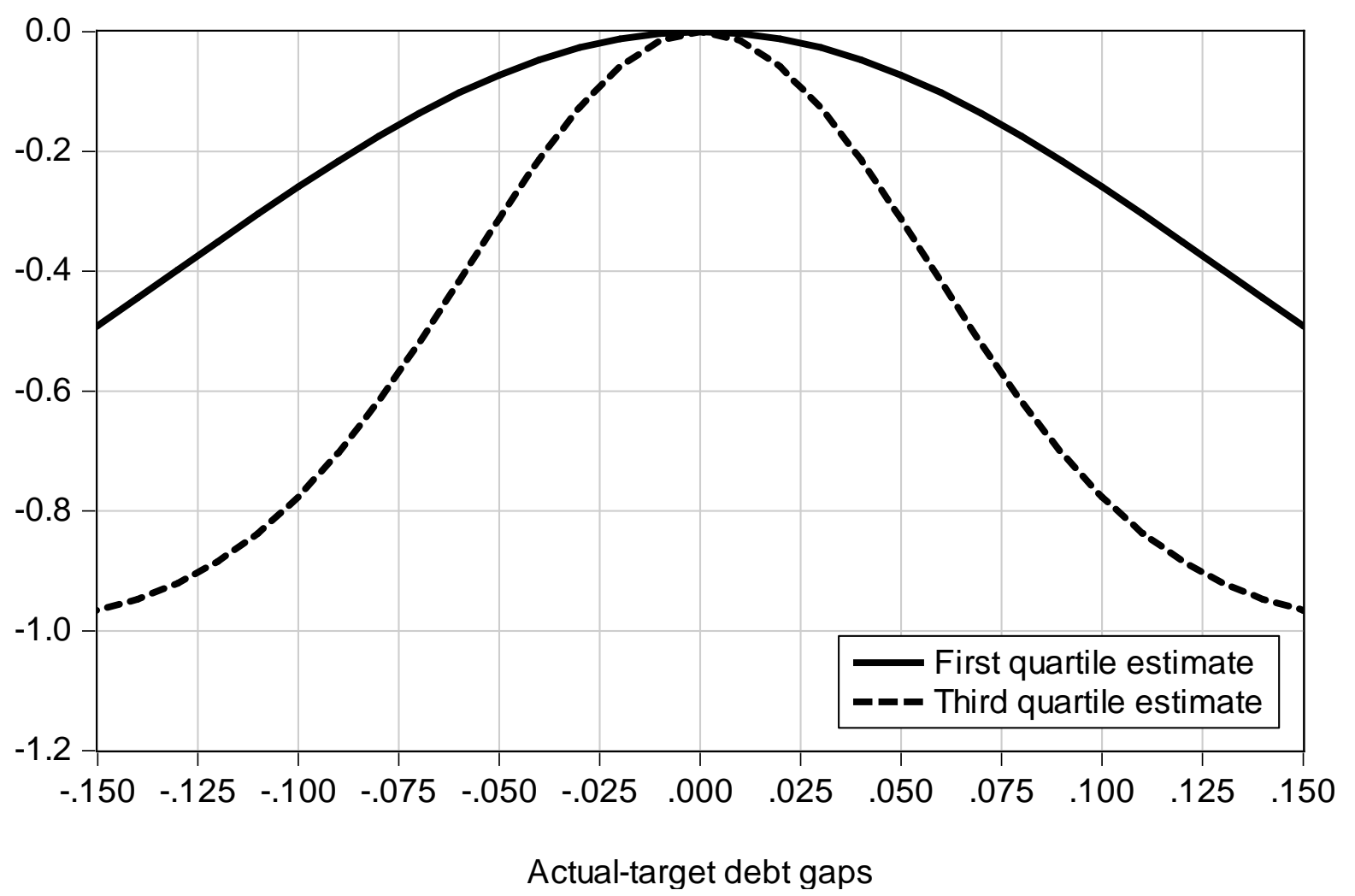

The two SOA estimates for different debt gaps are obtained by using the first and third quartile of the distribution of $\theta$ estimates in model (12). 
Fig. 2 - Counts of firms $(N)$ belonging to alternative fixed and rolling sub-samples ${ }^{a}$

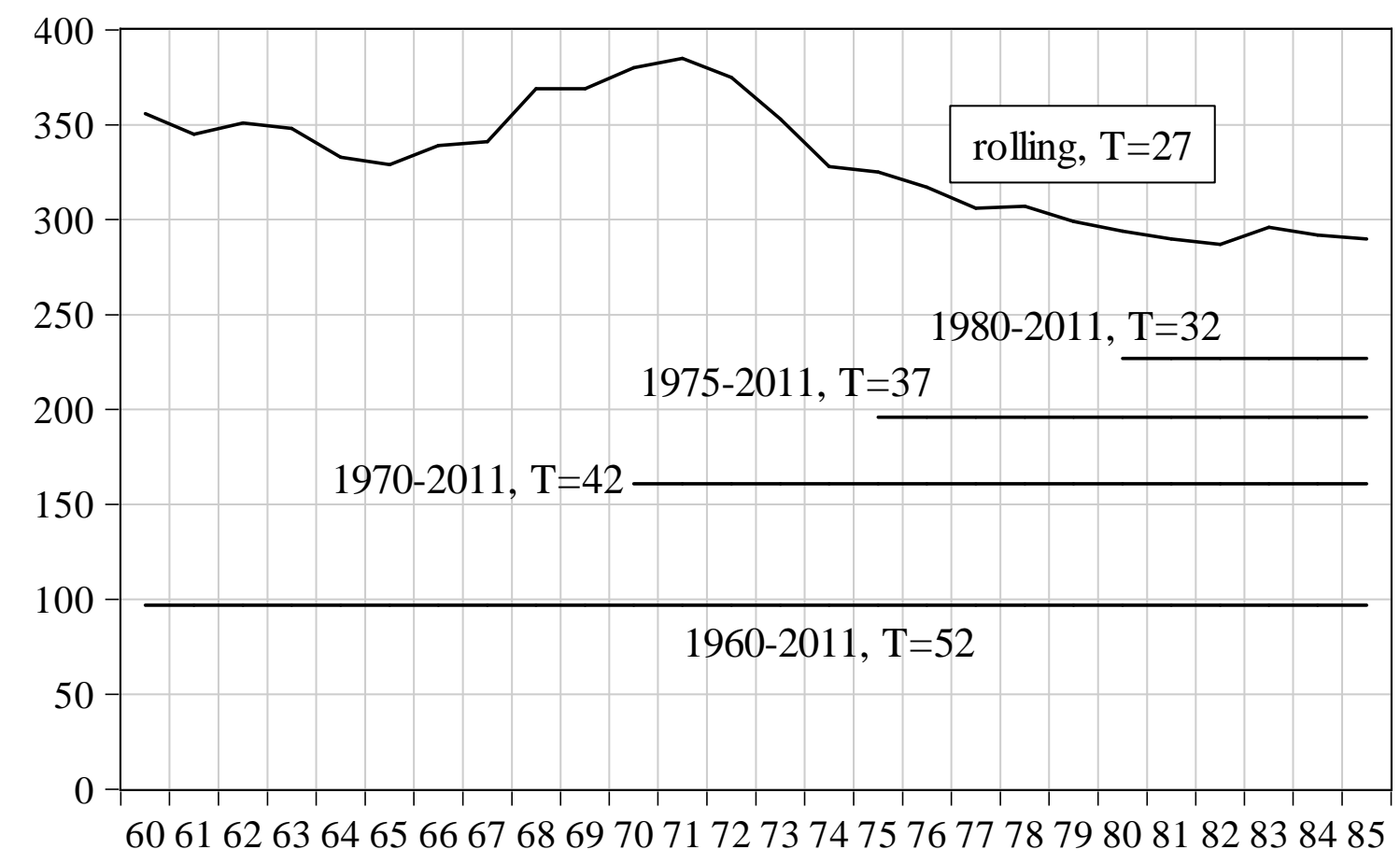

$\left.{ }^{(a}\right)$ Conventionally, the $\mathrm{x}$-axis reports the first year (begin) of the alternative the sub-sample periods.

Of course, for straight lines the sum of the begin year plus the labeled $T$ gives the end year of each fixed sub-period (always 2011), while the rolling sub-periods are defined form the beginning to 27 years later. 
Fig. 3 - Rolling estimates of reverting firms' shares (upper panel) and of average SOAs (lower panel) by debt term structure ${ }^{a}$
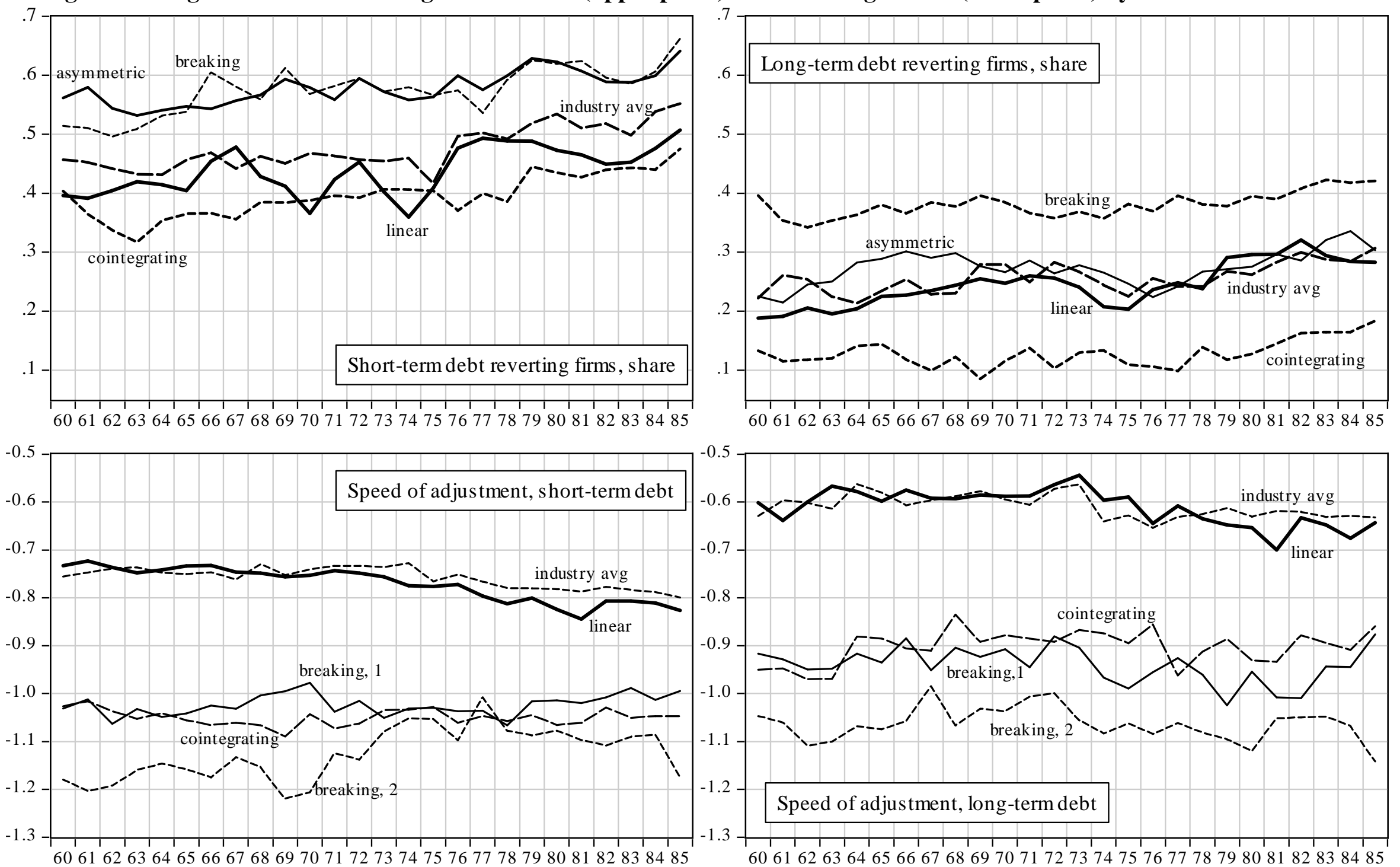

$\left({ }^{a}\right)$ Conventionally, the horizontal axes report the first year of the alternative rolling sub-samples with a 27 -years window over which shares and average SOAs are estimated. 
Tab. A3.1 - Sample distribution by industry and average debt-ratios

\begin{tabular}{lrrrrr}
\hline & & & \multicolumn{3}{c}{ Average debt ratios } \\
& Obs. & $\%$ & Total & Long-term & Short-term \\
\hline 1-Non Durables & 10,053 & 5.96 & 0.237 & 0.167 & 0.070 \\
2-Durables & 4,570 & 2.71 & 0.238 & 0.159 & 0.078 \\
3-Manufacturing & 23,939 & 14.19 & 0.237 & 0.180 & 0.058 \\
4-Energy & 10,756 & 6.38 & 0.246 & 0.199 & 0.047 \\
5-Chemicals & 4,550 & 2.7 & 0.234 & 0.183 & 0.052 \\
6-Business Equipments & 20,909 & 12.39 & 0.151 & 0.095 & 0.056 \\
7-Telcommunications & 5,875 & 3.48 & 0.370 & 0.321 & 0.050 \\
8-Utilities & 9,094 & 5.39 & 0.416 & 0.367 & 0.049 \\
9-Trade, shops & 11,283 & 6.69 & 0.256 & 0.178 & 0.078 \\
10-Hotels & 12,665 & 7.51 & 0.177 & 0.126 & 0.051 \\
11-Finance & 29,630 & 17.56 & 0.216 & 0.139 & 0.077 \\
12-Other & 25,372 & 15.04 & 0.259 & 0.198 & 0.061 \\
Total & 168,696 & 100 & 0.238 & 0.176 & 0.062 \\
\hline
\end{tabular}




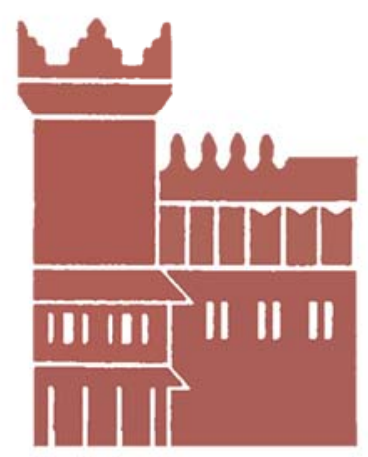

Alma Mater Studiorum - Università di Bologna DEPARTMENT OF ECONOMICS

Strada Maggiore 45

40125 Bologna - Italy

Tel. +39051 2092604

Fax +390512092664

http://www.dse.unibo.it 